May 2002 • NREL/TP-560-32063

\title{
Distributed Power Program DER Pilot Test at the Nevada Test Site
}

Benjamin Kroposki and Richard DeBlasio National Renewable Energy Laboratory

Joseph Galdo

U.S. Department of Energy

\section{National Renewable Energy Laboratory}

1617 Cole Boulevard

Golden, Colorado 80401-3393

NREL is a U.S. Department of Energy Laboratory

Operated by Midwest Research Institute • Battelle $\bullet$ Bechtel

Contract No. DE-AC36-99-G010337 
May 2002 • NREL/TP-560-32063

\section{Distributed Power Program DER Pilot Test at the Nevada Test Site}

Benjamin Kroposki and Richard DeBlasio National Renewable Energy Laboratory

Joseph Galdo

U.S. Department of Energy

Prepared under Task No. DPO2.1001

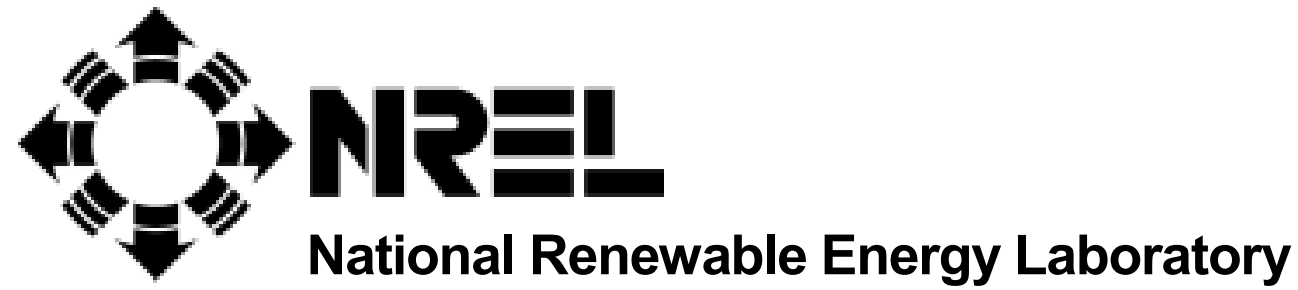

1617 Cole Boulevard

Golden, Colorado 80401-3393

NREL is a U.S. Department of Energy Laboratory

Operated by Midwest Research Institute $\bullet$ Battelle $\bullet$ Bechtel

Contract No. DE-AC36-99-G010337 


\section{NOTICE}

This report was prepared as an account of work sponsored by an agency of the United States government. Neither the United States government nor any agency thereof, nor any of their employees, makes any warranty, express or implied, or assumes any legal liability or responsibility for the accuracy, completeness, or usefulness of any information, apparatus, product, or process disclosed, or represents that its use would not infringe privately owned rights. Reference herein to any specific commercial product, process, or service by trade name, trademark, manufacturer, or otherwise does not necessarily constitute or imply its endorsement, recommendation, or favoring by the United States government or any agency thereof. The views and opinions of authors expressed herein do not necessarily state or reflect those of the United States government or any agency thereof.

Available electronically at http://www.osti.gov/bridge

Available for a processing fee to U.S. Department of Energy

and its contractors, in paper, from:

U.S. Department of Energy

Office of Scientific and Technical Information

P.O. Box 62

Oak Ridge, TN 37831-0062

phone: 865.576.8401

fax: 865.576 .5728

email: reports@adonis.osti.gov

Available for sale to the public, in paper, from:

U.S. Department of Commerce

National Technical Information Service

5285 Port Royal Road

Springfield, VA 22161

phone: 800.553 .6847

fax: 703.605.6900

email: orders@ntis.fedworld.gov

online ordering: http://www.ntis.gov/ordering.htm 


\section{Table of Contents}

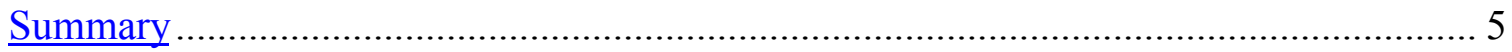

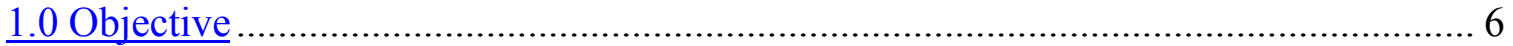

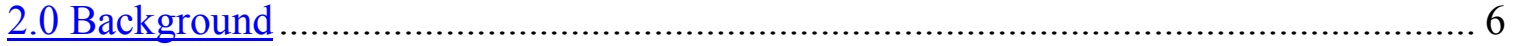

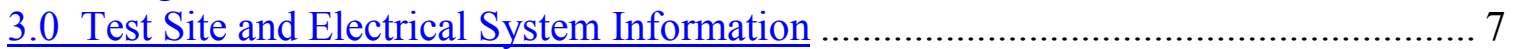

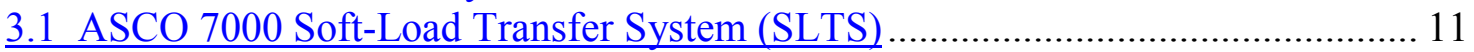

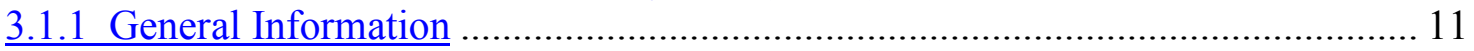

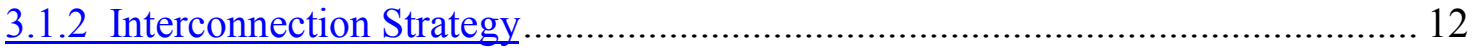

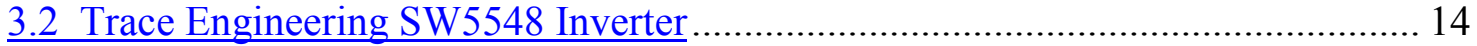

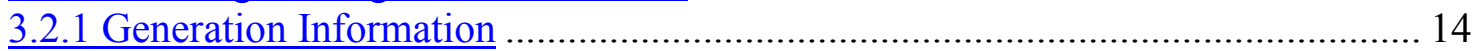

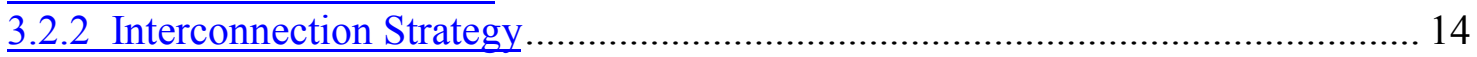

3.3 Data Acquisition Equipment and Measurements ............................................... 16

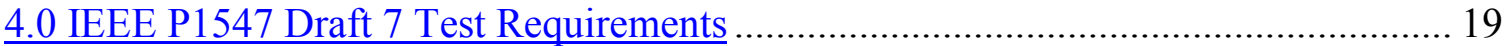

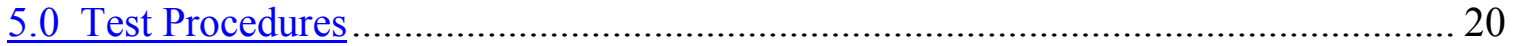

5.1 Over/Under Voltage and Over/Under Frequency Test ....................................... 20

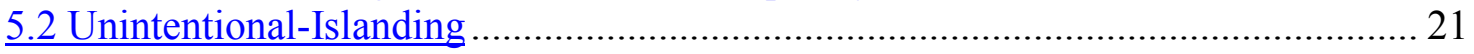

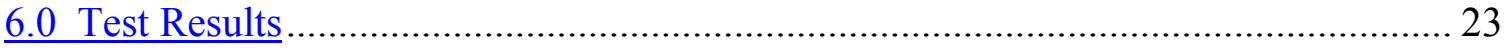

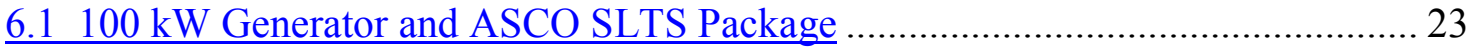

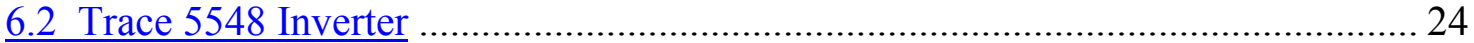

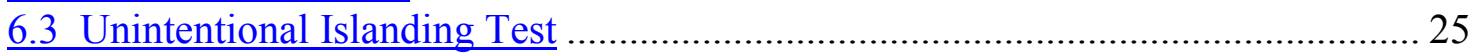

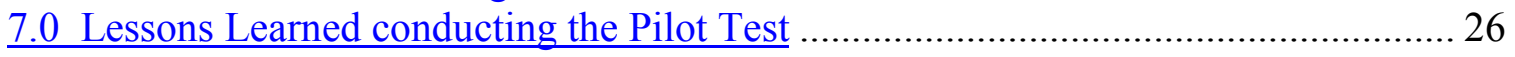

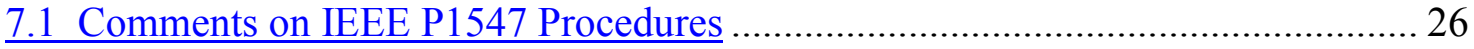

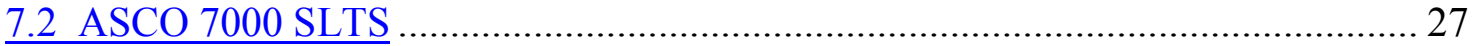

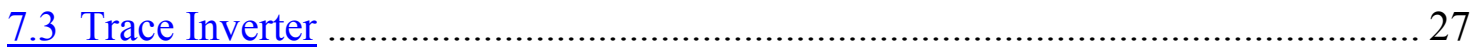

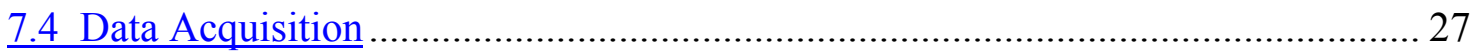

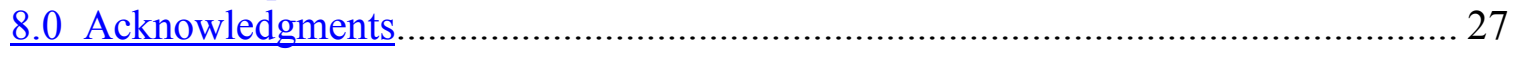

Appendix A - Test Procedures from IEEE P1547 Draft 7 …....................................... 28

Over-voltage (Simulated Utility or Secondary Injection) .................................... 28

Under-voltage (Simulated Utility or Secondary Injection) ........................................ 28

Over-frequency (Simulated Utility or Secondary Injection) ..................................... 28

Under-frequency (Simulated Utility or Secondary Injection) .................................. 29

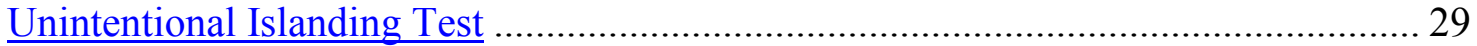




\section{List of Tables}

Table 1. ASCO SLTS Protective Settings …………….............................................. 13

Table 2. Trace Inverter Protective Function Settings ..................................................... 16

Table 3. Interconnection System Response to Abnormal Voltages................................... 19

Table 4. ASCO Over Voltage Test Data..................................................................... 23

Table 5. ASCO Under Voltage Test Data........................................................................ 23

Table 6. ASCO Over Frequency Test Data …………................................................. 23

Table 7. ASCO Under Frequency Test Data ……………….................................... 23

Table 8. Trace Inverter Voltage and Frequency Test Results......................................... 25

Table A1. Ratios of Real Load to DR Output................................................................... 31

\section{List of Figures}

(This page intentionally left blank) ............................................................................. 2

Figure 1. Picture of Nevada Test Site Location ................................................................. 7

Figure 2. Layout Drawing of Feeder 25-10-1202 at the Nevada Test Site Area 25 .......... 8

Figure 3. Aerial View of Test Area .......................................................................... 9

Figure 4. Picture of Feeder 25-10-1202 with equipment locations ................................. 9

Figure 5. Electrical One-Line Diagram of Test ………............................................... 10

Figure 6. Inside of ASCO SLTS …………………............................................... 12

Figure 7. Display on front of ASCO SLTS.................................................................. 12

Figure 8. Trace Engineering SW5548 Tested.............................................................. 14

Figure 9. Location of Measurement Equipment on ASCO SLTS ................................... 17

Figure 10. Cabinet containing Circuit Breakers and Current Transducers for ASCO

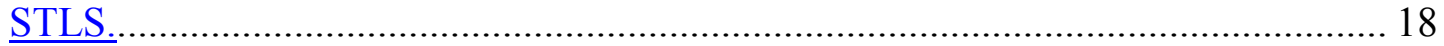

Figure 11. ASCO Over Frequency Disconnection Test................................................. 24

Figure 12. ASCO Under Frequency Disconnection Test................................................. 24

Figure 13. ASCO Under Voltage Disconnection Test (extended time period) ................ 24

Figure 14. ASCO Under Voltage Disconnection Test........................................................ 24

Figure 16. Trace Inverter Over Frequency Disconnection Test ..................................... 25

Figure 15. Trace Inverter Under Frequency Disconnection Test …………………….... 25

Figure 17. Trace Inverter Under Voltage Disconnection Test.......................................... 25

Figure 18. Electrical Diagram of Unintentional Island Test............................................... 26

Figure A1. Non-islanding Test Circuit ........................................................................ 30 


\section{Summary}

The Department of Energy (DOE) Distributed Power Program conducted a pilot test of certain interconnection test procedures from November 12-16, 2001, at Area 25 of the Nevada Test Site (NTS). The objective of this pilot test was to respond to Congressional direction in the Energy and Water Development Appropriations Act of 2001 to complete a distributed power demonstration at the Nevada Test Site and validate interconnection tests in the field.

The demonstration consisted of field verification of tests in IEEE P1547 (Draft 7) that are required for interconnection of distributed generation equipment to electrical power systems. Some validation of the testing has been conducted in a laboratory setting, but the Nevada Test Site provided a location to verify the interconnection tests in the field. The testing demonstration also provided valuable information for evaluating the potential for the Nevada Test Site to host future field-testing activities in support of Distributed Energy Resources System Integration R\&D.

The test procedures carried out consisted of verification of over/under voltage and frequency protective trip points, as well as a test for unintentional islanding. These tests were conducted on an ASCO soft-load transfer system (SLTS) connected to a $100 \mathrm{~kW}$ generator and a Trace SW5548 inverter. The ASCO SLTS tripped before the programmed set points for all of the tests. The Trace inverter met all of the test requirements for the over/under voltage and frequency tests except the unit did not trip on the over voltage setting due to test equipment limitations. Additionally, during the matched load part of the unintentional islanding test, it was observed that both the ASCO SLTS and the Trace inverter continued to run on in an island condition for up to 40 seconds.

Testing results also showed that it is difficult to conduct some of the draft test procedures in IEEE P1547 in the field. The results of these tests will be provided to the IEEE P1547 and P1589 working groups to help better define test procedures that can be used in verifying the interconnection equipment of distributed generation. 


\subsection{Objective}

The DOE Distributed Power Program conducted a pilot test of interconnection test procedures November 12-16, 2001, at Area 25 of the Nevada Test Site (NTS). The objective of this pilot test was to respond to Congressional direction in the Energy and Water Development Appropriations Act of 2001 to complete a distributed power demonstration at the Nevada Test Site and to validate interconnection tests in the field.

The demonstration consisted of field verification of certain proposed tests in IEEE P1547 (Draft 7) that are required for interconnection of distributed generation equipment to electrical power systems. Some of the testing has been previously validated in a laboratory setting, but the Nevada Test Site provided a suitable location to verify the interconnection tests in the field. The testing demonstration also provided valuable information for evaluating the potential for the Nevada Test Site to host future fieldtesting activities in support of Distributed Energy Resources System Integration R\&D.

\subsection{Background}

During the period from Summer 2000 to Summer 2001 several meetings were held between the Department of Energy HQ, DOE Nevada, Bechtel Nevada, the National Renewable Energy Laboratory (NREL), and the Idaho National Engineering and Environmental Laboratory (INEEL) to determine how to complete a demonstration project at the Nevada Test Site that would contribute useful research results in the area of interconnection of distributed generation with electric power systems. After a workshop with industry was conducted in November 2000, it was determined that conducting field validation of certain specified tests described in IEEE P1547 would yield the most valuable information. The field verification of the proposed test procedures in IEEE P1547 was considered extremely important by the attendees of the workshop. To conduct the field verification, a testing team was formed to run the pilot test project.

The testing team included partners from DOE, national laboratories, NTS Site Operation, and industry. The team was led by NREL, which developed the test plan and managed the overall project. Engineers from INEEL provided technical guidance and testing support. ASCO Power Technologies provided test equipment, as well as engineering and technician support during the testing. Bechtel Nevada and DOE Nevada acted as site operators, provided site management, construction and electrician support for the project. 


\subsection{Test Site and Electrical System Information}

The Nevada Test Site is a national test site in south central Nevada, located north of Las Vegas by approximately 60 miles (Figure 1). The land area at the NTS is equivalent to that of the state of Rhode Island, and the site currently has 1,000 square miles of completely undisturbed land, potentially available for new projects. There is a significant amount of transmission, sub-transmission, and distribution level equipment installed within the NTS, most of which is operational, but some of which is not currently in use. The site further benefits from its close proximity to the DOE offices located north of Las Vegas.

Area 25 is located in the southwest corner of the Nevada Test Site. There are a substation, distribution feeder system, and assorted buildings and electrical loads located within Area 25. Area 25 is the specific site that has been identified as a possible venue for integrated testing of Distributed Resources (DR).

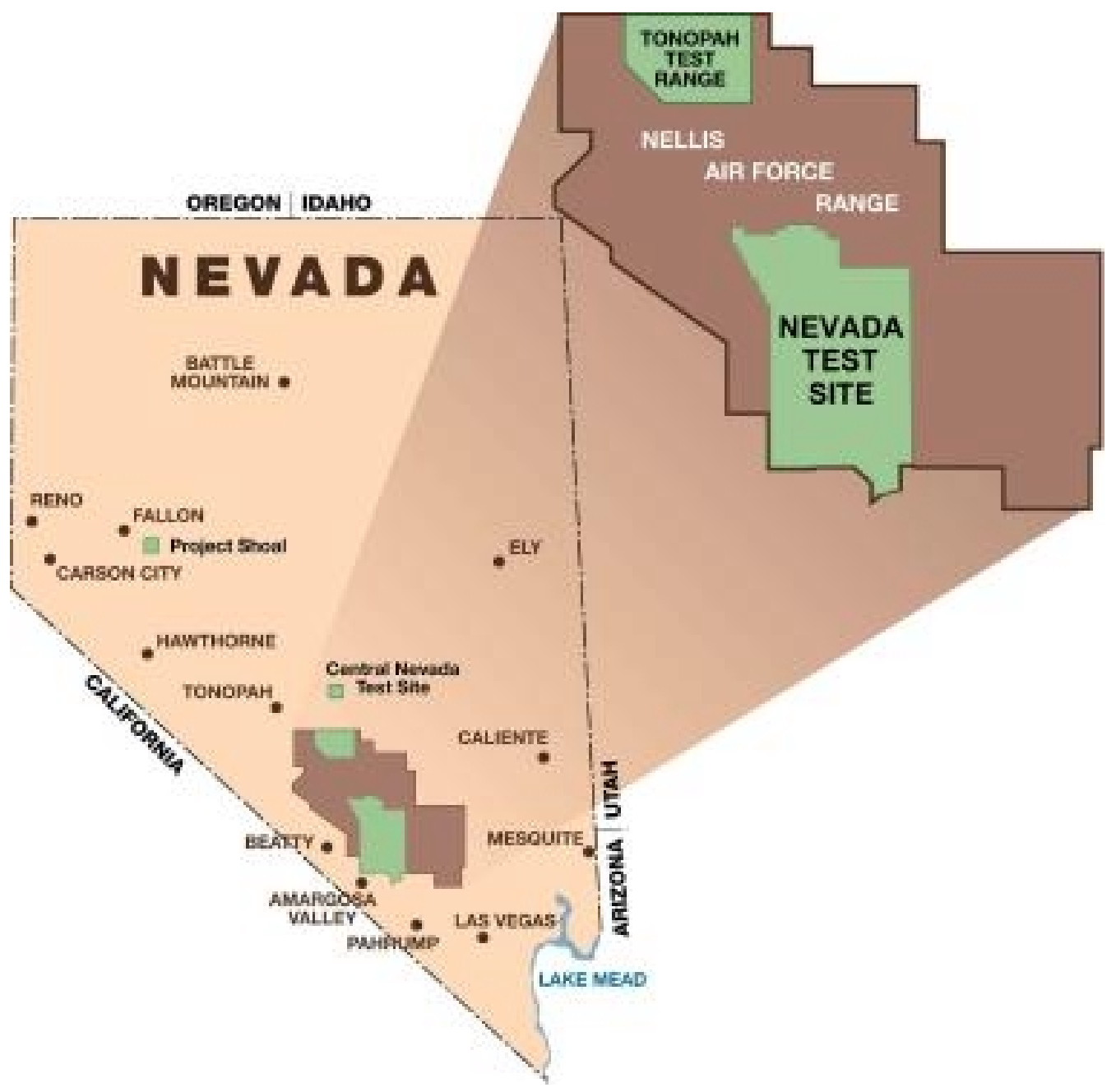

Figure 1. Picture of Nevada Test Site Location 
When the NTS site was first considered, a number of different substations and areas were reviewed. After reviewing the various aspects of the different areas available, the decision was made to use the site at Area 25. This site has an existing, under-utilized 2.5 MVA substation, a $12 \mathrm{kV}$ distribution system of approximately $1 / 6$ mile in length, relatively large building loads, and access to the electrical apparatus inventory on the NTS site ${ }^{1}$.

Testing was conducted on the Electrical Feeder (25-10-1202) in Area 25 of the Nevada Test Site. Figure 2 gives an overview of the electrical feeder. The total length of the feeder was approximately 1/6 mile. Area 25 has an existing substation that is designated as 25-10 on the site drawings. This substation was originally installed to service local building loads when the site was active and operational. The substation has a $2.5 \mathrm{MVA}$ transformer with $69 \mathrm{kV}$ primary and $12.4 \mathrm{kV}$ secondary. The transformer is a $7.08 \%$ impedance transformer and has multiple taps at $\pm 2.5 \%$ and $\pm 5 \%$ ratings. Other important apparatus at the substation includes circuit breakers and sectionalizing circuit breakers for separate feeders 1202 and 1203. Figure 3 gives an aerial photograph of the electrical feeder. Figure 4 shows another view of the feeder with the test area, utility simulator, and substation highlighted.

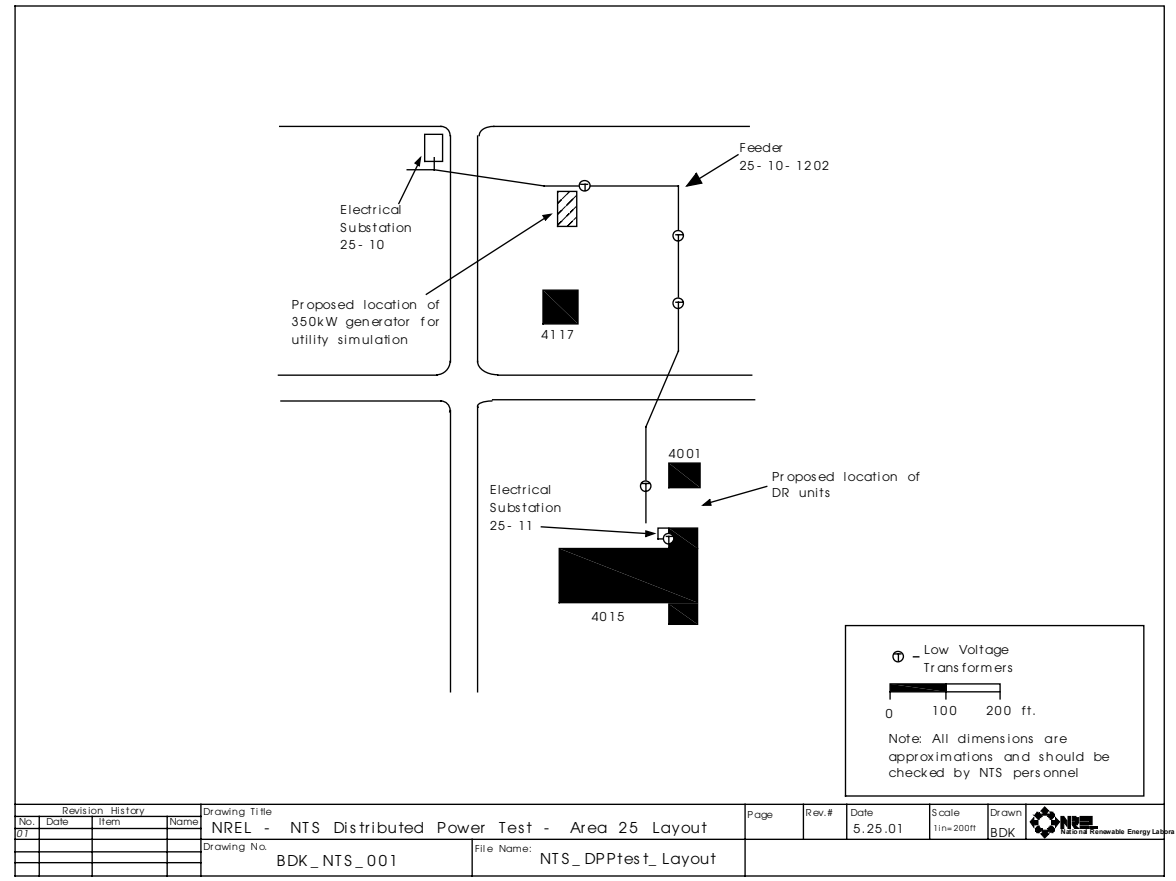

Figure 2. Layout Drawing of Feeder 25-10-1202 at the Nevada Test Site Area 25

${ }^{1}$ Originally, a different area of the NTS, the Mercury substation area was being considered. However, the Mercury area is a site where a significant amount of activity continues to occur, and there are no plans that would cause this activity to diminish. Because of this activity, the site was excluded. An unused site where distribution testing could be performed without concern for power disruption to adjacent customers is considered an important requirement for DR testing. 


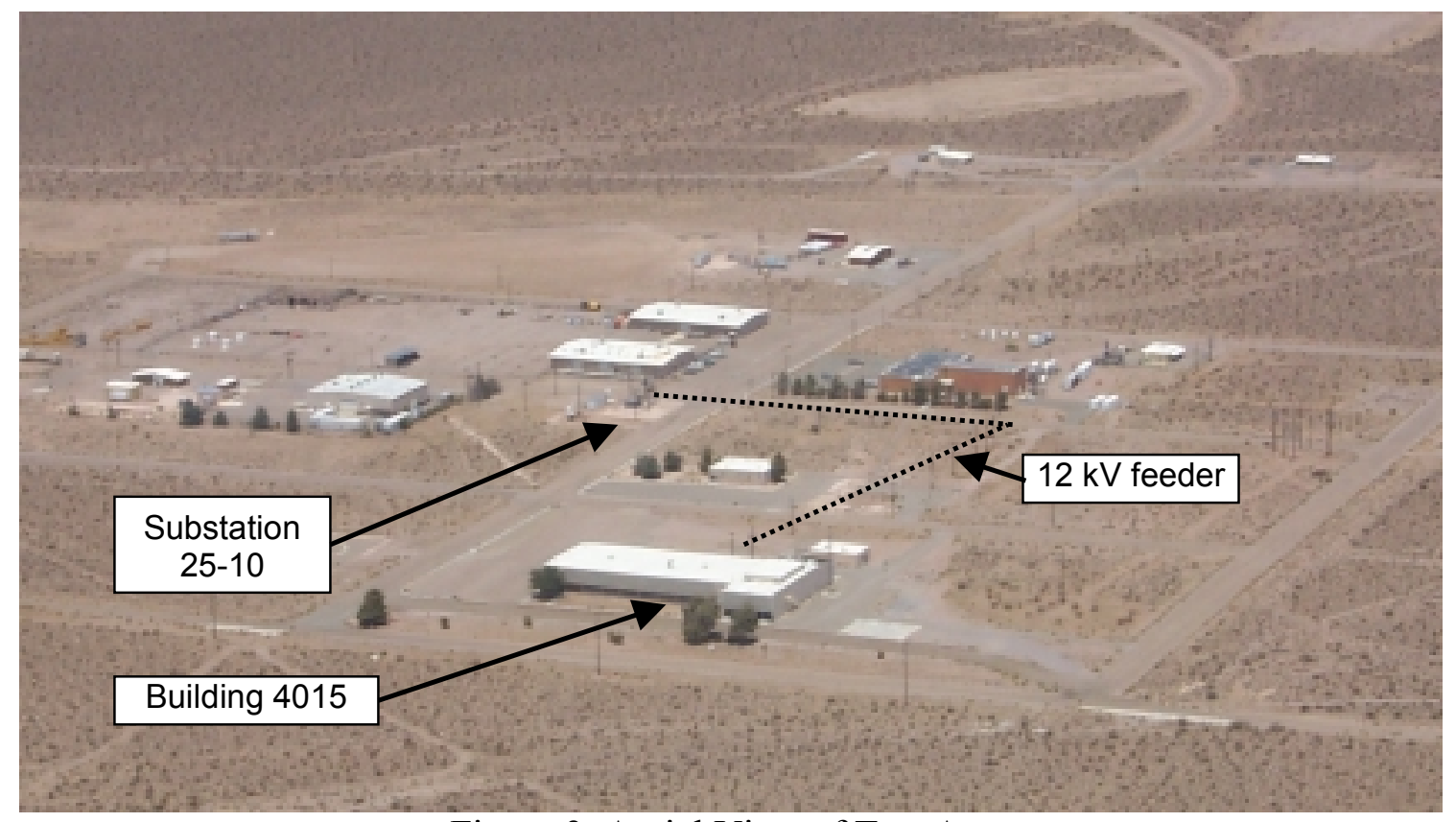

Figure 3. Aerial View of Test Area

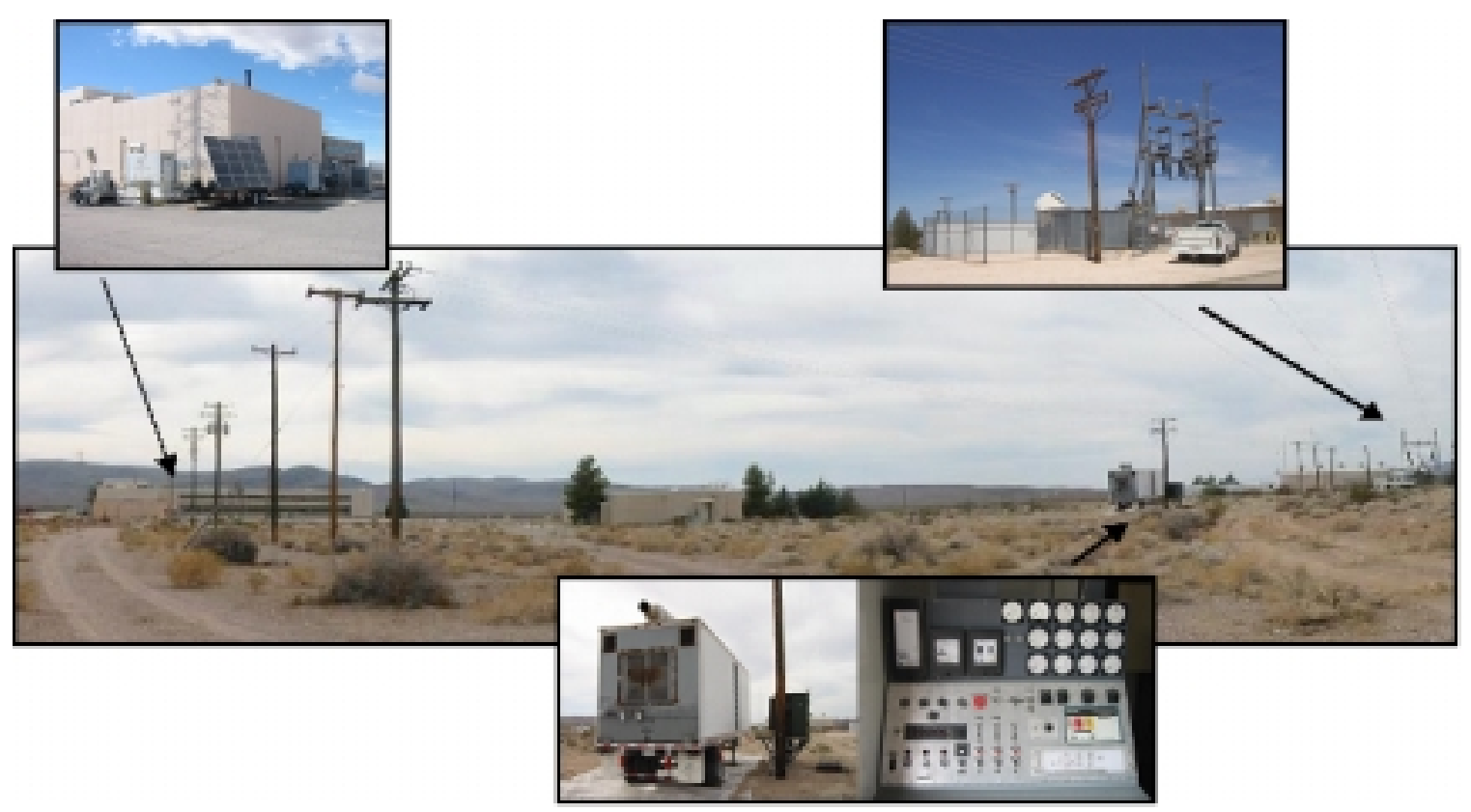

Figure 4. Picture of Feeder 25-10-1202 with equipment locations 
The interconnection devices that were tested were from two different distributed resources: 1) Static Inverter [Trace Engineering $5 \mathrm{~kW}$, Model 5548PV] and 2) Synchronous generator $[100 \mathrm{~kW}$ diesel gensets with ASCO 7000 series soft-load transfer system (SLTS)]. Variable load banks available at the NTS, and available loads in nearby site buildings that are currently out of service were used for loading the DR units. Additionally, two large portable loads were rented to supplement the existing equipment. A large portable diesel genset ( $350 \mathrm{~kW}$ with voltage and frequency control) was used as a utility grid simulator. Figure 5 shows an electrical one-line for the test set up.

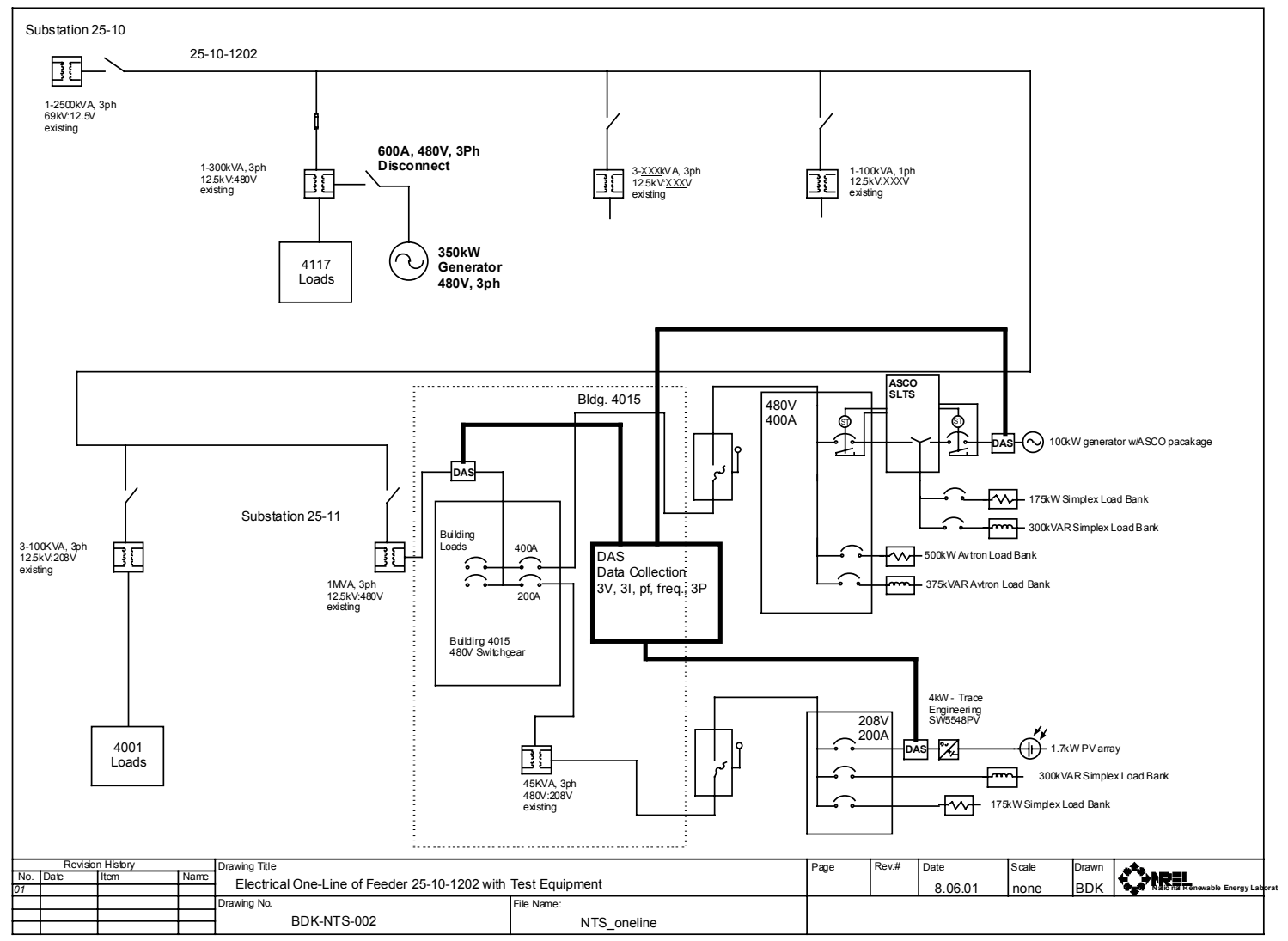

Figure 5. Electrical One-Line Diagram of Test 


\subsection{ASCO 7000 Soft-Load Transfer System (SLTS)}

\subsubsection{General Information}

The ASCO 7000 soft-load transfer system is designed to transfer between a utility and generator sources. The system components consist of a soft load controller, graphical user interface, transfer switch controller, and electronic access modules, fully integrated into a complete soft-load control system.

Specific Equipment connected to ASCO SLTS:

DR:

$100 \mathrm{~kW}$ diesel generator connected to the emergency terminals of the SLTS

Governor: $\quad$ Woodward 2301, PN 8271-442, SN 2085356, Analog input: 0-5

VDC

Voltage Regulator: $\quad$ Basler SR4F3, PN 59700101, SN 1102, Analog input: ${ }^{+} / .9$ VDC

VAR/pf Controller: Basler SCP 250-G-60

Operating Modes: There are three modes of operation possible when the distributed resource (DR) is operated in parallel with the electric power system (EPS).

1. Base Load - In the base load mode, the DR is synchronized and paralleled with the EPS. The DR is then set to operate at a specified load in $\mathrm{kW}$ and power factor. The DR controller then adjusts, or "biases" fuel and excitation controllers to maintain the output to the set points.

2. Import - In the import mode, the DR is synchronized and paralleled with the EPS. The DR is then set to import a specified load in $\mathrm{kW}$ and control the generator power factor to the setting. The DR controller then biases fuel and excitation controllers to maintain the output to the set points. The load on the DR will vary as a function of the SLTS load. Generator loading is equal to the SLTS load minus the import setting.

3. Export - In the export mode, the DR is synchronized and paralleled with the EPS. The $\mathrm{DR}$ is then set to export a specified load in $\mathrm{kW}$ and control the generator power factor to the setting. The DR controller then biases fuel and excitation controllers to maintain the output to the set points. The load on the DR will vary as a function of the SLTS load. Generator loading is equal to the sum of the SLTS load plus the export setting. 


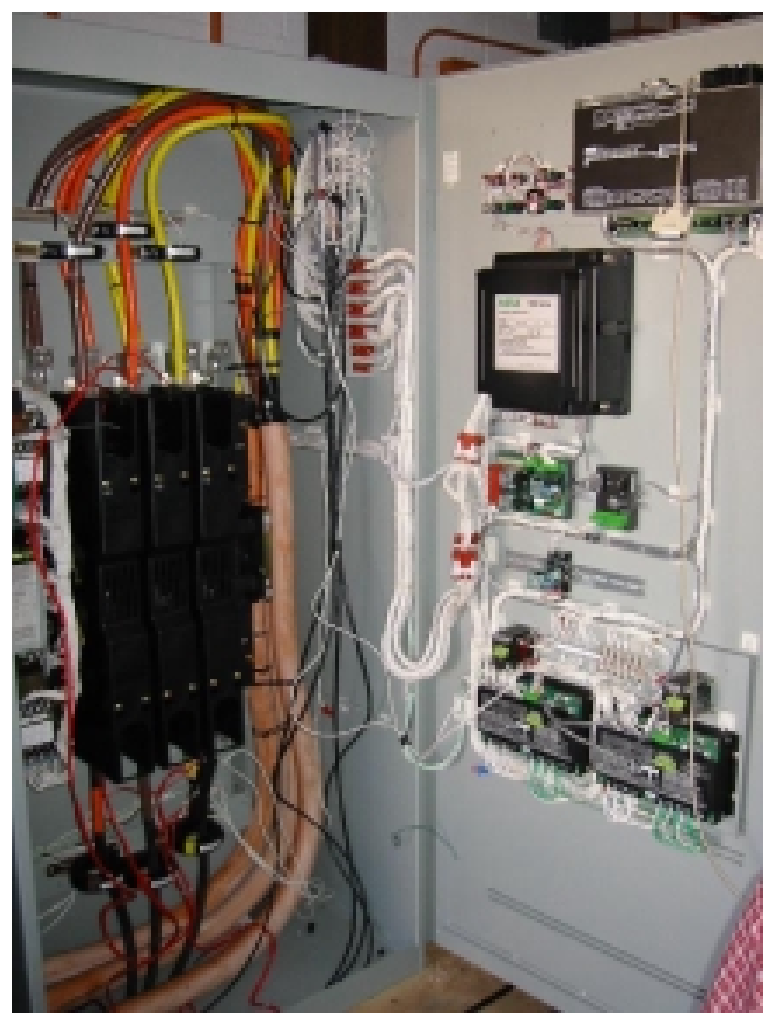

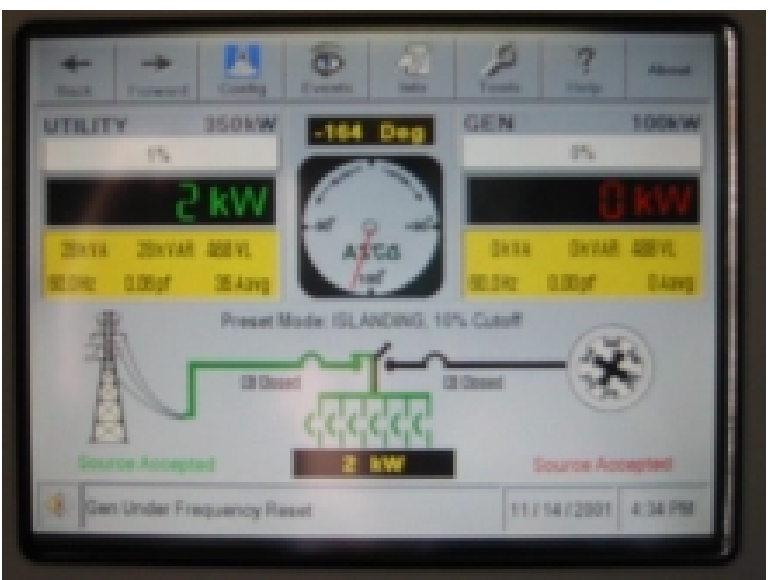

Figure 7. Display on front of ASCO

SLTS

Figure 6. Inside of ASCO SLTS

\subsubsection{Interconnection Strategy}

The interconnect strategy under investigation in this test program assumes that the DR is an existing on-site generator, the primary function of which is to provide power to mission-critical loads during those times when EPS power is inadequate in capacity or quality, or unavailable. Regardless of the operating mode, detection of EPS events that lead to islanding and separation of the DR from the EPS is a prime objective. The DR must disconnect, or separate, from the EPS before it can be damaged or tripped off the line, so that it can be ready to assume its prime objective. Accordingly, the protective functions specified in P1547 and incorporated in the tests described herein are set to separate the DR from the EPS. The control strategy assumes that once the sources are separated, their respective protective functionality will then sort out the cause and initiate the proper response.

In brief, if the initiating action is a fault on the EPS system, the directional overcurrent function of the control strategy should separate the generator from the EPS with no intentional delay. This acts to separate the sources before a recloser can operate. Sectionalizing of an EPS radial is typically the result of a recloser opening to clear a fault and then reclosing with no intentional delay on the first reclose. The shortest total time for this is 12 cycles. Thus the separation of the DR should occur in less than 12 cycles. 
Where the EPS failure is one of decaying voltage, the under voltage trip function should operate. Depending on the rate of voltage decay, the directional overcurrent function might also operate in response to attempts to control power factor. However, it might take longer for the trip to occur. Separation should occur within the time setting of the under voltage trip delay once the trip setting is reached.

The specific interconnect system used to conduct the test regimen regarding is furnished as follows:

ASCO 800 A ATSE with SLC

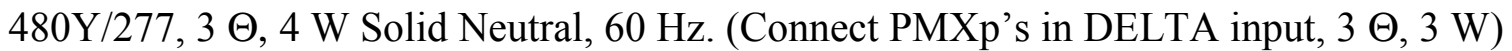

N\&E CTs $150: 5$

Protective Device Settings are given in Table 1.

Table 1. ASCO SLTS Protective Settings

\begin{tabular}{|c|c|c|c|c|}
\hline \multirow{2}{*}{ Function } & \multicolumn{2}{|c|}{ TRIP } & \multicolumn{2}{|c|}{ RESET } \\
\hline & Setting & Time & Setting & Time \\
\hline \multicolumn{5}{|l|}{ Utility } \\
\hline Undervoltage & $88 \%$ & $2 \mathrm{sec}$. & $95 \%$ & 2 sec. \\
\hline Overvoltage & $110 \%$ & $1 \mathrm{sec}$. & $107 \%$ & 2 sec. \\
\hline Underfrequency & $59.4 \mathrm{~Hz}$ & $2 \mathrm{sec}$ & $60.0 \mathrm{~Hz}$ & $2 \mathrm{sec}$ \\
\hline Voltage Unbalance & $10 \%$ & $2 \mathrm{sec}$. & $7 \%$ & 2 sec. \\
\hline Current Unbalance & $10 \%$ & $2 \mathrm{sec}$. & $7 \%$ & 2 sec. \\
\hline Reverse Power/Underpower & $+5 \%$ & $2 \mathrm{sec}$. & $+7 \%$ & 2 sec. \\
\hline Reverse Overcurrent & $100 \%$ & Inst. & 0 & $1 \mathrm{sec}$. \\
\hline \multicolumn{5}{|l|}{ Generator } \\
\hline Undervoltage & $70 \%$ & $0.2 \mathrm{sec}$. & $95 \%$ & 2 sec. \\
\hline Overvoltage & $115 \%$ & $0.2 \mathrm{sec}$. & $110 \%$ & 2 sec. \\
\hline Underfrequency & $57 \mathrm{~Hz}$ & $0.2 \mathrm{sec}$. & $57.6 \mathrm{~Hz}$ & 2 sec. \\
\hline Overfrequency & $60.6 \mathrm{~Hz}$ & $0.2 \mathrm{sec}$. & $60.0 \mathrm{~Hz}$ & 2 sec. \\
\hline Overload, kW, alarm & $95 \%$ & $10 \mathrm{sec}$. & $90 \%$ & 2 sec. \\
\hline Overload, kW, Trip & $105 \%$ & $2 \mathrm{sec}$. & $97 \%$ & $10 \mathrm{sec}$. \\
\hline Reverse Power & $-5 \%$ & $2 \mathrm{sec}$. & $-2 \%$ & 2 sec. \\
\hline Excess Reverse VARs & $20 \%$ & Inst & 0 & 2 sec. \\
\hline Ramp Time & $15 \mathrm{sec}$. & & & \\
\hline Power Factor & 0.90 & & & \\
\hline Function & \multicolumn{2}{|c|}{ Trip } & \multicolumn{2}{|c|}{ Reset } \\
\hline & Setting & Time & Setting & Time \\
\hline \multicolumn{5}{|l|}{ Generator (cont.) } \\
\hline Minimum Load & $10 \%$ & & & \\
\hline Maximum Load & $100 \%$ & & & \\
\hline \multicolumn{5}{|l|}{ System } \\
\hline Islanding Mode & & & & \\
\hline Utility cutoff & $10 \%$ & & & \\
\hline
\end{tabular}




\subsection{Trace Engineering SW5548 Inverter}

\subsubsection{Generation Information}

The Trace engineering inverter (Figure 8) is designed to be connected to a DC source (Photovoltaics and/or battery bank) and produce AC power. The SW5548 has a 48 volt DC input and produces up to $5500 \mathrm{VA}$ at $120 \mathrm{~V}$ single-phase AC power. For this testing, the unit was connected to a battery bank and was used in a grid-connect inverter/charge mode that allowed the inverter to send power to the utility or take power from the utility to charge the batteries.

The Trace SW series uses a combination of three transformers, each with its own low frequency switcher, coupled together in series and driven by separate interconnected micro-controllers. In essence, it is three inverters linked together by their transformers. By mixing the outputs from the different transformers, a stepped approximation of a sine wave is produced. The total harmonic distortion in the Trace Engineering SineWave design approach is typically $3-5 \%$. The multi-stepped output is formed by modulation of the voltage through mixing of the three transformers in a specific order. Anywhere from 34-52 "steps" per AC cycle may be present in the waveform. The heavier the load or the lower the DC input voltage, the more steps that are utilized to create the waveform. ${ }^{2}$

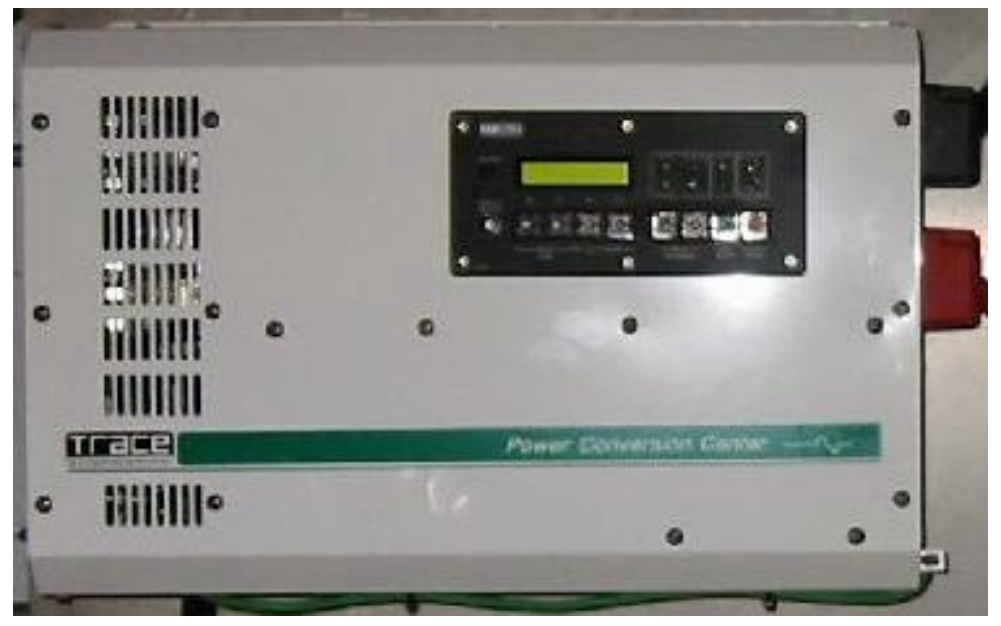

Figure 8. Trace Engineering SW5548 Tested

\subsubsection{Interconnection Strategy}

The SW series inverter uses four protection systems to prevent the occurrence of an inverter "islanding" (continuing to power a disconnected section of the utility distribution system). This section summarizes the design theory of operation of the protection systems and gives the default values and adjustment range for the settings, which are adjustable.

\footnotetext{
2 “A Review of Inverter Design and Topologies” Trace Engineering (2/00)
} 
When the protection system senses the loss of utility power, an internal contactor is opened to disconnect the inverter from the utility. The contactor is a normally open type, which disconnects the utility whenever the inverter is turned off or shuts down due to an error condition. The inverter can continue operating loads connected directly to the inverter output terminals when a power outage occurs. This can provide a utility backup function for loads wired to a separate subpanel connected to the inverter's output terminals. The loads will operate from power generated by the solar array and/or the power stored in the battery.

Once the utility line has returned to an acceptable condition for 90 seconds, the inverter synchronizes with the utility line. Once synchronized, the inverter must maintain synchronization for 5 minutes before it closes the input contactor. When the contactor closes, the inverter can either charge the battery from the utility or sell excess solar power to the utility, if "SELL" mode is enabled. Up to 60 amps can be passed through the inverter from the utility when the inverter is utility intertied.

The utility interactive protection systems are as follows:

Overcurrent - The inverter will instantly shutdown if the instantaneous current being supplied in to the utility grid exceeds an internally set threshold. This protects the power transistors primarily, but also is the first protection system tripped when the utility system is de-energized. This is caused by the inverter attempting to power all of the loads still connected to the distribution system. The inverter sees the utility as a short circuit of its output, and affects a shut down. The inverter will only be able to attempt to "island" if the utility grid is divided into a small enough section with a connected load below the inverter's output ability. The overcurrent trip level is typically at 78 amps AC and is reduced based on the power transistor's heatsink temperature.

Over / Under Voltage - When set to "SELL" mode, the inverter watches the RMS voltage of the utility and disconnects if the values go outside of the non-adjustable window. This provides protection during brown-outs and utility "sags," and thus is the likely protection function activated when the utility's voltage changes slowly. The lower limit value was set to $107 \mathrm{VAC}$ and the upper limit was set to 128 VAC.

Over / Under Frequency - When in "SELL" mode, the inverter stays locked "synchronized" to the utility frequency and will disconnect if it drops below 59.3 $\mathrm{Hz}$ or rises above $60.5 \mathrm{~Hz}$. When utility power is connected and sensed, within the limits, the inverter does not attempt to control the utility power frequency therefore, if an islanding condition occurs, a frequency drift would result in an unacceptable mode condition in a short period of time. These values comply with UL1741 requirements, are factory set, functionally tested, and are not adjustable.

Zero Crossing Detection - The SW series inverter includes an additional protective system that watches the utility waveform and waits for the utility's 
voltage to increase above $4 \mathrm{VAC}$ before it starts to invert. This occurs during each cycle. If utility power is not present, voltage will not increase and no power inject by the inverter will occur. This feature also keeps multiple SW series inverters from creating a mini-island - since each unit will wait for a voltage reference to follow.

As mentioned earlier, the over current protection is the most often used protect of the inverter's four systems in the event of a grid disruption. A maximum delay of 1 cycle (20 milliseconds) might occur with respect to some of the protection systems other than overcurrent in order to reduce nuisance tripping from occurring. The overcurrent protection has no delay and responds in less than 4 milliseconds, but then tries several quick start attempts before shutting down. The inverter itself also includes a thermal/magnetic circuit breaker on its output as a backup level of protection. ${ }^{3}$ Table 2 lists the protective setting used during the tests for the Trace inverter.

Table 2. Trace Inverter Protective Function Settings

\begin{tabular}{|l|l|}
\hline Protective Function & Set Point \\
\hline Over Frequency & $60.5 \mathrm{~Hz}$ \\
\hline Under Frequency & $59.3 \mathrm{~Hz}$ \\
\hline Over Voltage & $128 \mathrm{~V}$ \\
\hline Under Voltage & $107 \mathrm{~V}$ \\
\hline
\end{tabular}

\subsection{Data Acquisition Equipment and Measurements ${ }^{4}$}

Data Acquisition for the test consisted of portable equipment that could be installed in the field with minimal disruption to the electrical interconnection system. The voltage and current of the ASCO STLS were monitored by both a Yokogawa 16 channel scope and two Power Measurements (PMI) 7600. The ASCO switch had six CTs that monitored three-phase current into the SLTS and 3 CTs that monitored current to the local loads. A diagram describing the measurement points for the ASCO SLTS is shown in Figure 9.

To monitor the current and voltage of the Trace inverter, a Yokogawa PZ4000 power analyzer and a Drantez Power Platform 4300 were used. The voltage and current measurements were made with voltage probes and clamp-on CTs attached at the $208 \mathrm{~V}$ distribution panel.

\footnotetext{
3 “SW Series Anti-Islanding Protective Systems" Xantrex Fact Sheet

${ }^{4}$ NREL does not endorse specific manufacturer's equipment for data acquisition. It is given only as an example of equipment that may be used.
} 


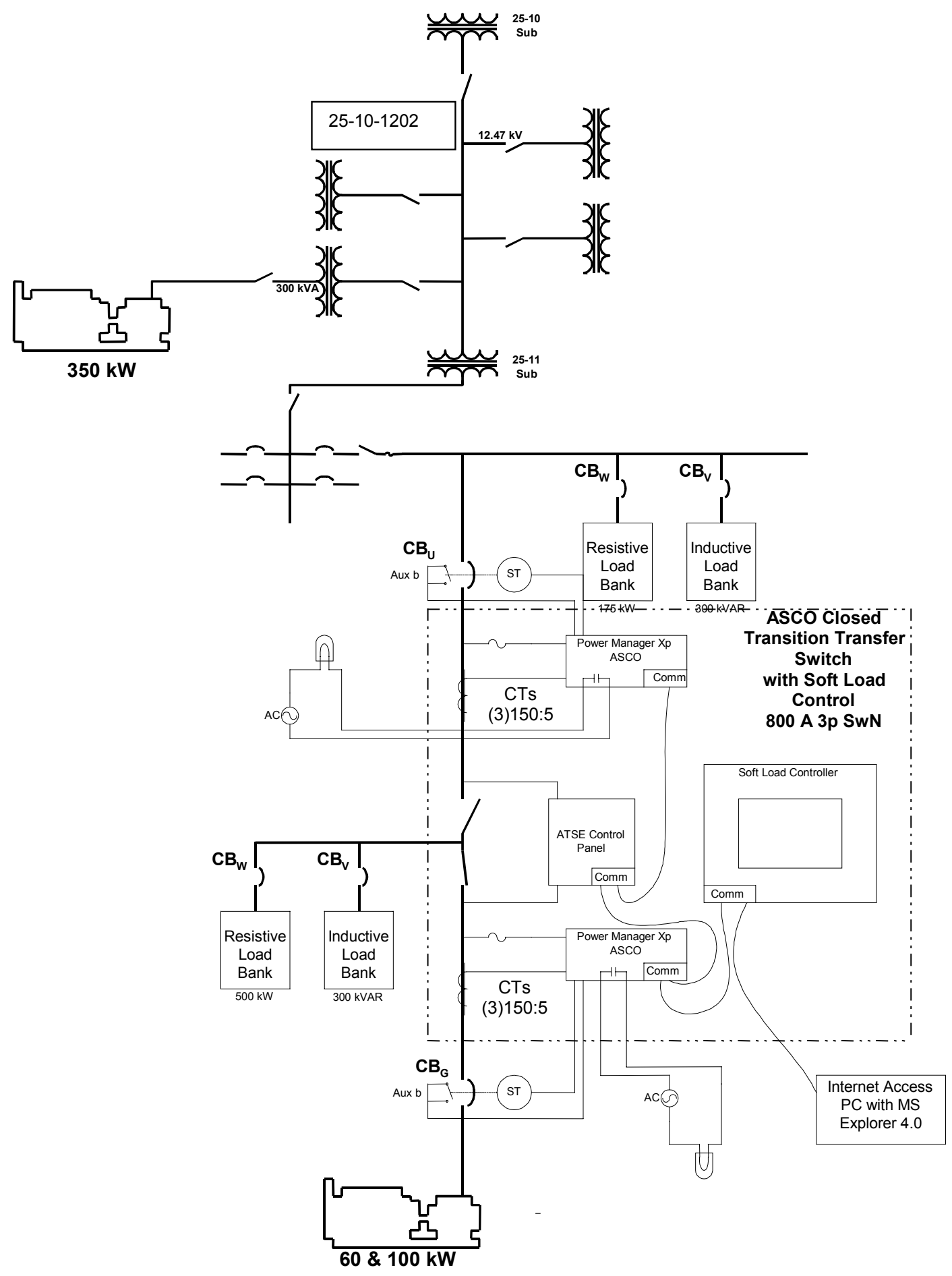

Figure 9. Location of Measurement Equipment on ASCO SLTS 


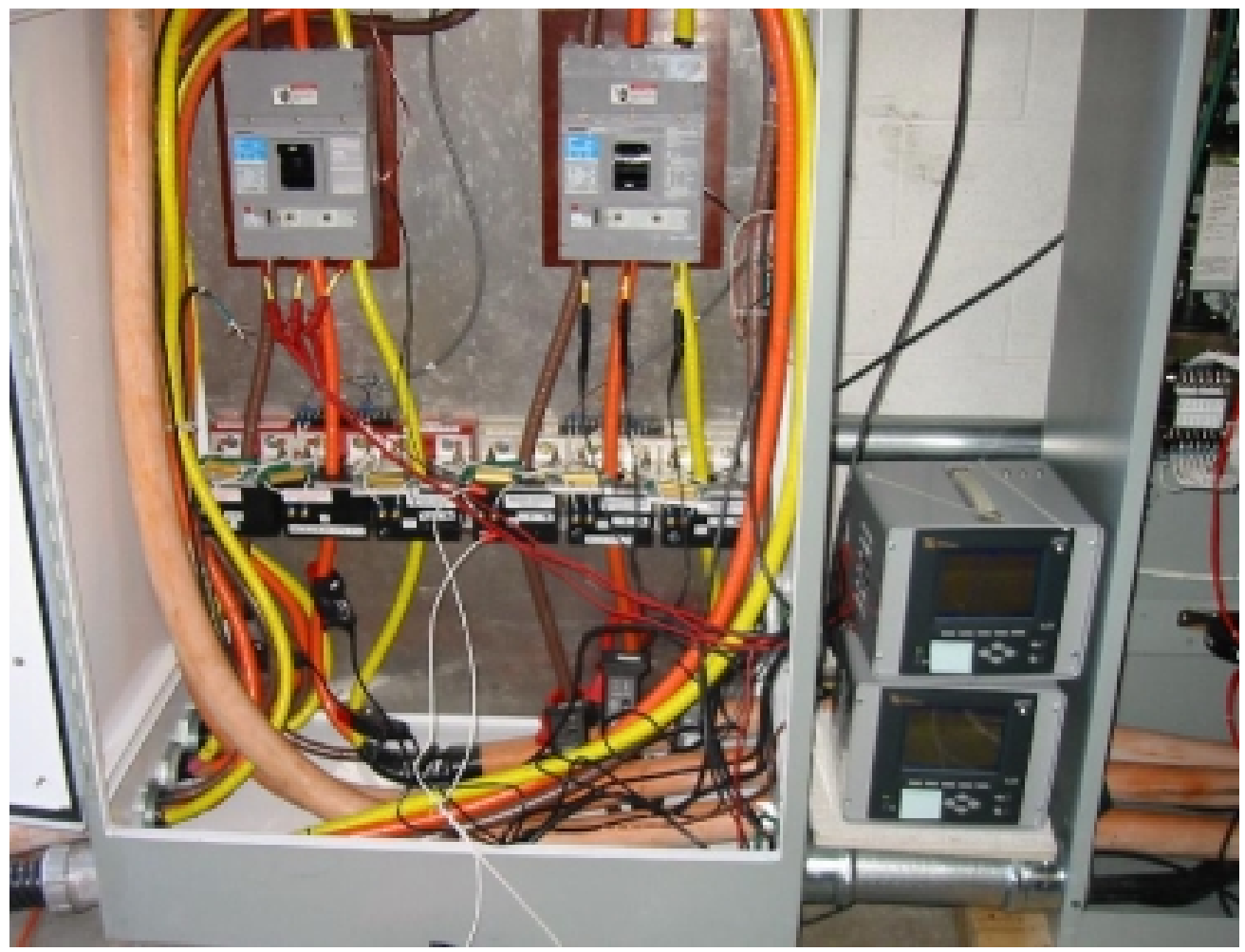

Figure 10. Cabinet containing Circuit Breakers and Current Transducers for ASCO STLS. 


\subsection{IEEE P1547 Draft 7 Test Requirements}

IEEE P1547 sets forth specific requirements for response to abnormal area EPS conditions. Requirements for voltage disturbances are given in Table 3.

Table 3. Interconnection System Response to Abnormal Voltages

\begin{tabular}{|l|l|}
\hline Voltage Range (\% of base voltage) & \multicolumn{1}{c|}{ Clearing Time (s)* } \\
\hline $\mathrm{V}<50$ & 0.16 \\
\hline $50 \leq \mathrm{V}<88$ & 2 \\
\hline $110<\mathrm{V}<120$ & 1 \\
\hline $\mathrm{V} \geq 120$ & 0.16 \\
\hline \multicolumn{2}{|c|}{ Note. Base voltages are the nominal voltages stated in ANSI C84.1. } \\
\hline$* \mathrm{DR} \leq 30 \mathrm{~kW}$, Maximum Clearing Times; DR $>30 \mathrm{~kW}$, Default Clearing Times \\
\hline
\end{tabular}

For frequency disturbances, IEEE P1547 states that all DR units shall follow the interconnected Area EPS frequency within the range $59.3 \mathrm{~Hz}$ to $60.5 \mathrm{~Hz}$ (on a $60 \mathrm{~Hz}$ base). The frequency measurements shall be either at the point of DR connection or PCC. A DR unit $<30 \mathrm{~kW}$ shall cease to energize the Area EPS within 0.16 second if the frequency goes outside the range above. A DR unit $>30 \mathrm{~kW}$ shall (1) cease to energize the Area EPS within 0.16 second if the frequency exceeds $60.5 \mathrm{~Hz},(2)$ be capable of time delayed disconnection with adjustable under-frequency settings in the range $59.3 \mathrm{~Hz}$ to $57 \mathrm{~Hz}$, and (3) disconnect within 0.16 second if the frequency is less than $57.0 \mathrm{~Hz}$.

IEEE P1547 also has a requirement that for an unintentional island in which the DR and a portion of the Area EPS remain energized through the PCC, the DR shall cease to energize the Area EPS within 10 seconds of the formation of an island.

To validate the performance of the interconnection system, specific test procedures are set forth in the P1547 Appendix to test the specified requirements. These are provided in the Appendix of IEEE P1547 and are included in Appendix A of this document. The following selected commissioning and interconnection tests from IEEE P1547 were conducted.

- Over Voltage

- Under Voltage

- Over Frequency

- Under Frequency

- Unintentional-Islanding

With respect to the testing reported herein, certain modifications to the test procedures specified in IEEE P1547 Draft 7 were made because of equipment available at the test site. 
These modifications included:

1) All phase voltage and frequencies were adjusted simultaneously because the utility simulator was a generator and did not have independently adjustable voltage and frequency on each phase.

2) The unintentional-islanding test was modified to not include a capacitive load. To simulate the island condition, a matched resistive and inductive load was used.

3) Nominal system voltage was set to $460 \mathrm{~V}$ instead of $480 \mathrm{~V}$ due to the protective functions of the utility simulator prohibited excessively high voltages.

4) The Trace inverter was only tested one time instead of five consecutive times for the voltage and frequency tests because of the length of time required for the unit to reset (5 $\mathrm{min}$.).

\subsection{Test Procedures}

\subsection{Over/Under Voltage and Over/Under Frequency Test}

a) Isolate utility feeder 25-10-1202 at Sub 25-10 by opening the circuit feeder switch to circuit 25-10-1202. Lock this switch out and tag it.

b) Start $100 \mathrm{~kW}$ DR and Trace inverter. Both DR should be in a standby or idle condition.

c) Start the $350 \mathrm{~kW}$ utility simulator and connect it to feeder 25-10-1202.

d) The SLTS and inverter will connect to the simulated utility when power is available and adequate.

e) Connect building loads and load bank loads to achieve approximately $300 \mathrm{~kW}$ at approximately $0.9 \mathrm{pf}$. This includes any load fed by the SLTS. Set bus voltage and frequency to nominal, $460 \mathrm{VAC}, 60 \mathrm{~Hz}$.

f) Set the inverter to export $5 \mathrm{~kW}$.

g) Set SLTS load to approximately $50 \mathrm{~kW}, 0.9 \mathrm{pf}$.

h) Set SLTS operating mode to Import $25 \mathrm{~kW}, 0.9 \mathrm{pf}$.

i) Slowly reduce bus voltage at grid simulator to below lower voltage set point.

j) Note if the inverter tripped and if the SLTS normal source feeder breaker (UCB) tripped. DR returns to nominal voltage and continues to carry its load. Record trip point.

k) Reclose UCB, and restore bus voltage to 460 VAC nominal.

1) Restore inverter and STLS to normal operations.

m) Repeat items i-l five times.

n) Reclose UCB, and restore bus voltage to $460 \mathrm{VAC}$ nominal and restore inverter and STLS to normal operations.

o) Slowly increase bus voltage at grid simulator to above upper voltage set point.

p) Note if the inverter tripped and if the SLTS normal source feeder breaker (UCB) tripped. DR returns to nominal voltage and continues to carry its load. Record trip point.

q) Reclose UCB, and restore bus voltage to $460 \mathrm{VAC}$ nominal and restore inverter and STLS to normal operations.

r) Repeat items o-q five times. 
s) Reclose UCB, and restore bus voltage to $460 \mathrm{VAC}$ nominal and restore inverter and STLS to normal operations.

t) Slowly decrease bus frequency at grid simulator to below lower frequency set point.

u) Note if the inverter tripped and if the SLTS normal source feeder breaker (UCB) tripped. DR returns to nominal voltage and continues to carry its load. Record trip point.

v) Reclose UCB, and restore bus frequency to $60 \mathrm{~Hz}$ nominal and restore inverter and STLS to normal operations.

w) Repeat items t-v five times.

$\mathrm{x})$ Reclose UCB, and restore bus frequency to $60 \mathrm{~Hz}$ nominal and restore inverter and STLS to normal operations.

y) Slowly increase bus frequency at grid simulator to above upper frequency set point.

z) Note if the inverter tripped and if the SLTS normal source feeder breaker (UCB) tripped. DR returns to nominal voltage and continues to carry its load. Record trip point.

aa) Reclose UCB, and restore bus frequency to $60 \mathrm{~Hz}$ nominal and restore inverter and STLS to normal operations.

bb) Repeat items y-aa five times.

cc) Reclose UCB and restore bus frequency to nominal. After SLTS restores to the Import mode and stable operation, testing can be resumed for any load and pf conditions and settings.

\subsection{Unintentional-Islanding}

a) Isolate utility feeder 25-10-1202 at Sub 25-10 by opening the circuit feeder switch to circuit 25-10-1202. Lock this switch out and tag it.

b) Shut off all unnecessary loads fed from feeder 25-10-1202.

c) Start the $350 \mathrm{~kW} \mathrm{DR}$ and connect it to feeder 25-10-1202.

d) The SLTS will connect its load to the normal source terminals when power is available and adequate.

e) Connect building loads and load bank loads to achieve approximately $300 \mathrm{~kW}$ at approximately 0.9 pf. This includes any load fed by the SLTS. Set bus voltage and frequency to nominal, $480 \mathrm{VAC}, 60 \mathrm{~Hz}$.

f) Set SLTS load to approximately $50 \mathrm{~kW}, 0.9 \mathrm{pf}$.

g) Set SLTS operating mode to Import $25 \mathrm{~kW}, 0.9 \mathrm{pf}$.

h) When stabile operation is achieved, disconnect the $350 \mathrm{~kW}$ DR at Blgd. 4117. Note if the SLTS normal source feeder breaker (UCB) tripped, SLTS Normal source contacts open, and DR assumes and continues to carry the SLTS load.

i) Reconnect the $350 \mathrm{~kW}$ DR to the feeder bus at Bldg. 4117. Reclose UCB and note SLTS resumes Import mode at $25 \mathrm{~kW}$ and $0.9 \mathrm{pf}$.

j) Terminate SLTS Import operating mode. Note that DR disconnects and shuts down.

k) Turn off all load on feeder 25-10-1202. Turn SLTS load on. Measure load at the $350 \mathrm{~kW}$ DR and add load to the SLTS until DR loading is approximately $80 \mathrm{~kW}$. Measure and record load and power factor.

Note: At this point, the only load on the SLTS will be its load bank setting plus parasitic system load. 
1) Set the SLTS load setting to equal the recorded load and power factor obtained from the immediately preceding step.

m) Initiate Import Mode on the SLTS. When the DR is interconnected and stability is achieved, open the DR disconnect at Bldg. 4117 and note the SLTS normal source feeder breaker (UCB) tripped SLTS Normal source contacts open. DR assumes and continues to carry the SLTS load.

n) Reset system and controls and introduce whatever realistic scenarios can occur to further evaluate the interconnection protective relaying strategy. 


\subsection{Test Results}

Setup and testing was conducted over a four-day period (Nov. 12-16, 2001) at the test site.

\subsection{0 kW Generator and ASCO SLTS Package}

Tables 4-7 give the protective settings and actual trip values for the over/under voltage and frequency tests conducted on the ASCO SLTS. Each test was conducted five times and showed good repeatability for the tests. The ASCO SLTS tripped before the programmed set points for all parts of the test.

\begin{tabular}{|r|c|r|r|}
\hline \multicolumn{4}{|l|}{ T1. Over Voltage Test Data } \\
\hline \multicolumn{1}{|r|}{} & \multicolumn{2}{|c|}{ Trip } \\
\hline Trial \# & Time & Setting & Actual \\
\hline 1 & $18: 20: 06$ & 506 & 500.8 \\
\hline 2 & $18: 21: 38$ & 506 & 497.1 \\
\hline 3 & $18: 38: 38$ & 506 & 500.8 \\
\hline 4 & $18: 40: 06$ & 506 & 500.8 \\
\hline 5 & $18: 41: 25$ & 506 & 500.8 \\
\hline Avg & & & 500.06 \\
\hline Max & & & 500.80 \\
\hline Min & & & 497.10 \\
\hline Std Dev & & & 1.65 \\
\hline
\end{tabular}

Table 4. ASCO Over Voltage Test Data

\begin{tabular}{|c|c|c|c|}
\hline \multicolumn{4}{|c|}{ T2. Under Voltage Test Data } \\
\hline & & & rip \\
\hline Trial \# & Time & Setting & Actual \\
\hline 1 & $17: 59: 05$ & 418.6 & $\overline{412.4}$ \\
\hline$\overline{2}$ & $18: 11: 31$ & $\overline{418.6}$ & $\overline{412.4}$ \\
\hline 3 & $18: 12: 50$ & $\overline{418.6}$ & $\overline{412.4}$ \\
\hline$\overline{4}$ & $18: 13: 58$ & 418.6 & 412.4 \\
\hline 5 & $18: 14: 55$ & $\overline{418.6}$ & 408.8 \\
\hline Avg & & & 411.68 \\
\hline $\operatorname{Max}$ & & & 412.40 \\
\hline Min & & & 408.80 \\
\hline$\overline{\text { Std Dev }}$ & & & 1.61 \\
\hline
\end{tabular}

Table 5. ASCO Under Voltage Test Data

\begin{tabular}{|r|r|r|c|}
\hline \multicolumn{4}{|c|}{ T3. Over Frequency Test Data } \\
\hline \multicolumn{2}{|r|}{} & \multicolumn{2}{|c|}{ Trip } \\
\hline Trial \# & & Setting & Actual \\
\hline 1 & $9: 42: 07$ & 60.6 & 60.6 \\
\hline 2 & $9: 51: 02$ & 60.6 & 60.2 \\
\hline 3 & $9: 56: 53$ & 60.6 & 60.6 \\
\hline 4 & $9: 59: 25$ & 60.6 & 60.6 \\
\hline 5 & $10: 01: 00$ & 60.6 & 60.6 \\
\hline Avg & & & 60.52 \\
\hline Max & & & 60.60 \\
\hline Min & & & 60.20 \\
\hline Std Dev & & & 0.18 \\
\hline
\end{tabular}

Table 6. ASCO Over Frequency Test Data

\begin{tabular}{|r|c|c|c|}
\hline \multicolumn{4}{|c|}{ T4. Under Frequency Test Data } \\
\hline \multicolumn{2}{|r|}{} & \multicolumn{2}{|c|}{ Trip } \\
\hline Trial \# & & Setting & Actual \\
\hline 1 & $18: 50: 22$ & 57 & 56.8 \\
\hline 2 & $18: 55: 53$ & 57 & 57.1 \\
\hline 3 & $18: 57: 52$ & 57 & 57.1 \\
\hline 4 & $18: 59: 51$ & 57 & 57.1 \\
\hline 5 & $19: 01: 39$ & 57 & 57.1 \\
\hline Avg & & & 57.04 \\
\hline Max & & & 57.10 \\
\hline Min & & & 56.80 \\
\hline Std Dev & & & 0.13 \\
\hline
\end{tabular}

Table 7. ASCO Under Frequency Test Data

Figures 11 and 12 show the voltage waveforms during the over and under frequency tests. Figure 13 shows the voltage and current on one phase when the unit tripped for under voltage. The trip point is shown in a more expanded view in Figure 14. This 
figure shows that at the trip point (when the current goes to zero), the magnitude of the voltage is $412.4 \mathrm{~V}$. The RMS voltage value is $583 \mathrm{~V} / \sqrt{ } 2=412.4 \mathrm{~V}$.

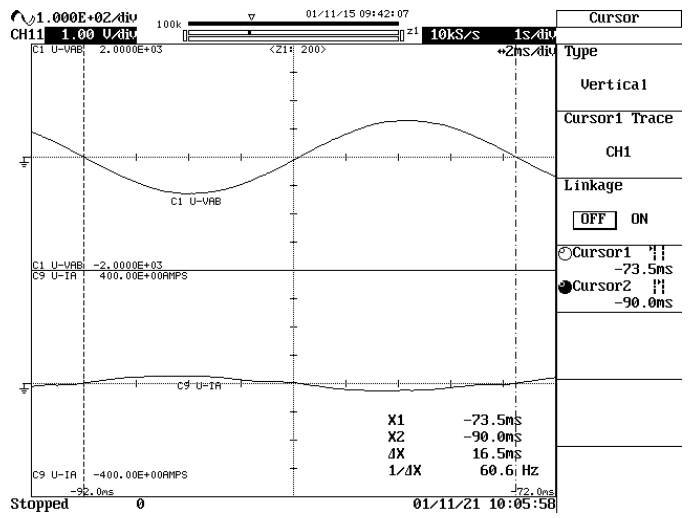

Figure 11. ASCO Over Frequency Disconnection Test

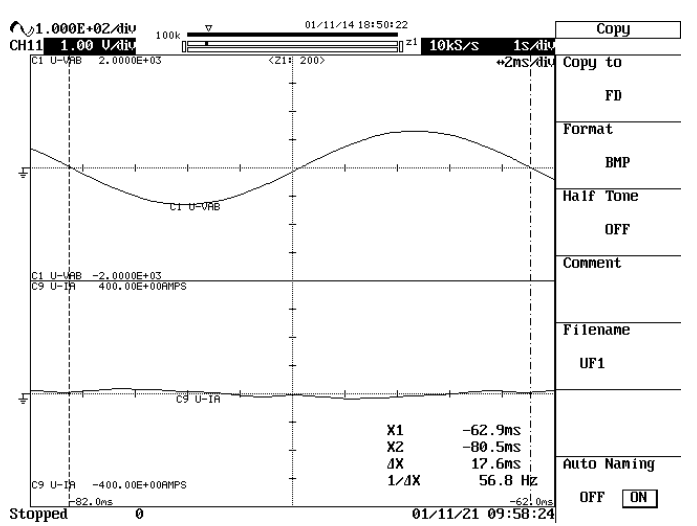

Figure 12. ASCO Under Frequency

Disconnection Test

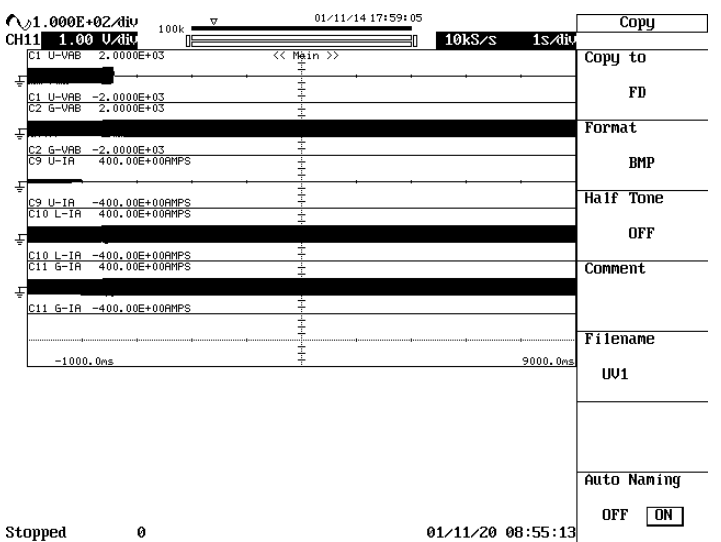

Figure 13. ASCO Under Voltage Disconnection Test (extended time period)

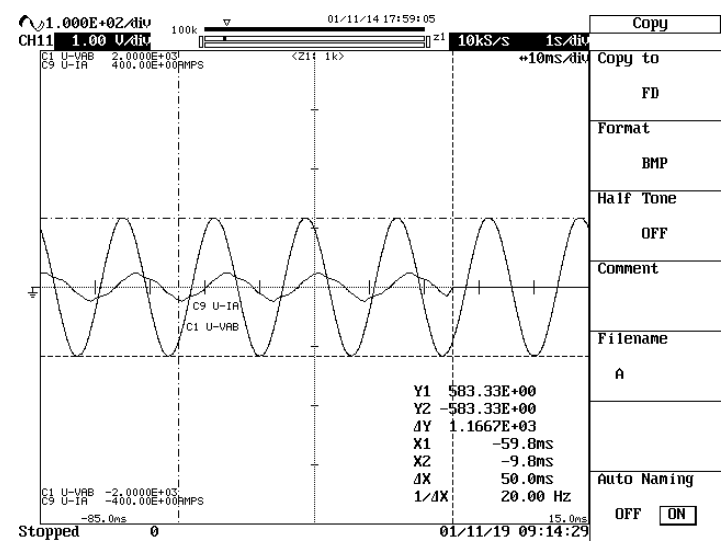

Figure 14. ASCO Under Voltage

Disconnection Test

\subsection{Trace 5548 Inverter}

Table 8 gives the protective set points and actual disconnect points for the Trace inverter. The Trace inverter met all of the test requirements for the over/under voltage and frequency tests except the unit did not trip on the over voltage setting as a result of test equipment limitations. The voltage on the utility simulator was not adjustable past $510 \mathrm{~V}$ (nominal $480 \mathrm{~V}$ ). This meant that the voltage on a $120 \mathrm{~V}$ nominal system could not be set higher than $127.5 \mathrm{~V}$ without rewiring the 480/208 V transformer. The lowest protective setting for the over voltage feature on the inverter is $128 \mathrm{~V}$; therefore the unit would not trip during the testing. Once the trip point is reached, the unit trips within 1 cycle for all tests. Figures 15-17 show the waveforms at the point of disconnection at the time the units tripped. 


\begin{tabular}{|l|l|l|}
\hline Test & $\begin{array}{l}\text { Set } \\
\text { Point }\end{array}$ & $\begin{array}{l}\text { Disconnect } \\
\text { Point }\end{array}$ \\
\hline $\begin{array}{l}\text { Over } \\
\text { Frequency }\end{array}$ & $60.5 \mathrm{~Hz}$ & $60.42 \mathrm{~Hz}$ \\
\hline $\begin{array}{l}\text { Under } \\
\text { Frequency }\end{array}$ & $59.5 \mathrm{~Hz}$ & $59.52 \mathrm{~Hz}$ \\
\hline $\begin{array}{l}\text { Over } \\
\text { Voltage }\end{array}$ & $128 \mathrm{~V}$ & $\begin{array}{l}\text { Did not trip } \\
\text { because of test } \\
\text { equipment }\end{array}$ \\
\hline $\begin{array}{l}\text { Under } \\
\text { Voltage }\end{array}$ & $107 \mathrm{~V}$ & $107.5 \mathrm{~V}$ \\
\hline
\end{tabular}

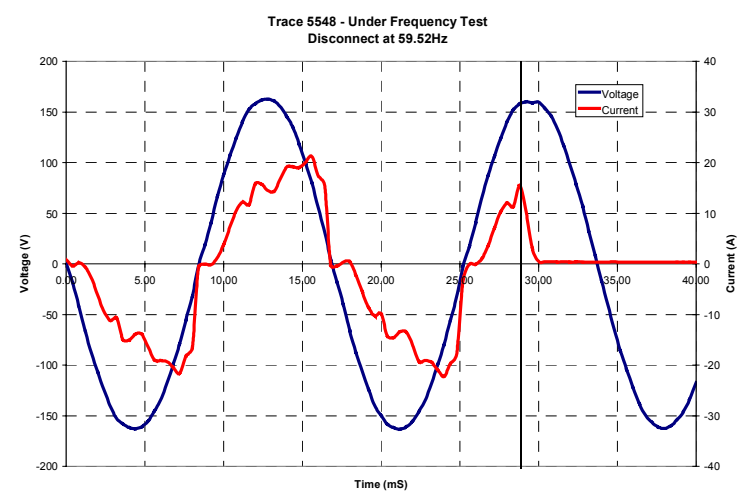

Figure 15. Trace Inverter Under Frequency Disconnection Test

Table 8. Trace Inverter Voltage and

Frequency Test Results

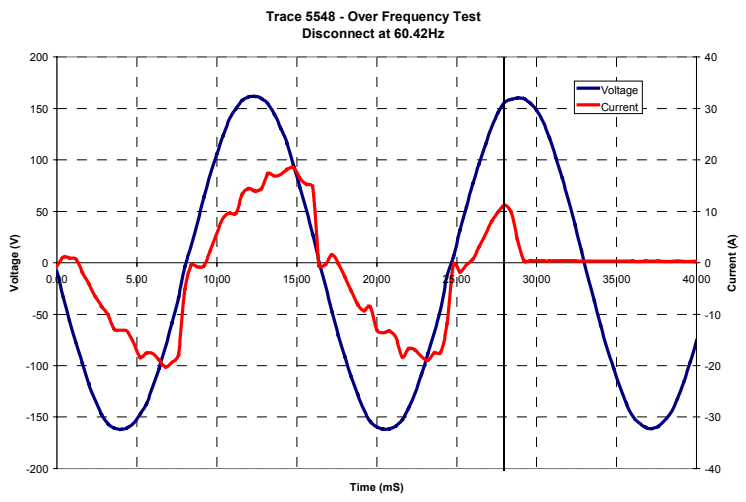

Figure 16. Trace Inverter Over Frequency Disconnection Test

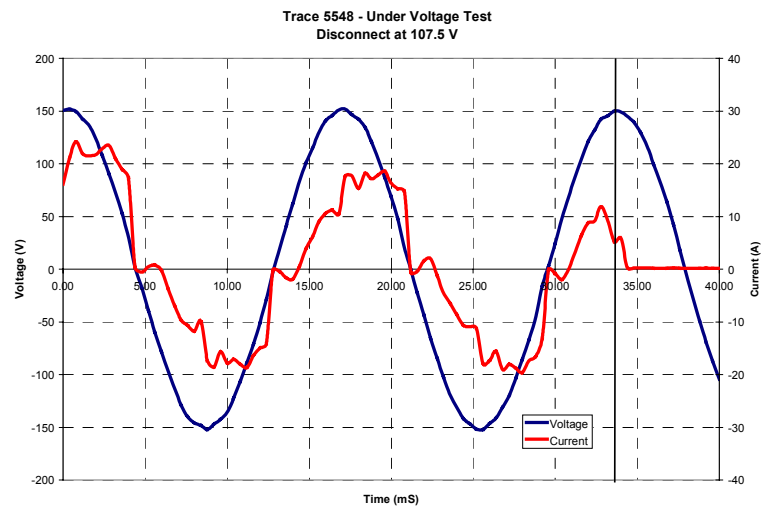

Figure 17. Trace Inverter Under Voltage Disconnection Test

\subsection{Unintentional Islanding Test}

The unintentional islanding test was configured as shown in Figure 18. Two conditions were tested. The first was an import condition of $25 \mathrm{~kW}$ for the ASCO STLS. This means that $25 \mathrm{~kW}$ of power was being required from the simulated utility across switch S1. Once this condition was stabilized, the switch S1 was opened to create the island. During this test the ASCO unit and Trace inverter quickly recognized when the switch S1 was open and disconnected within the required 2 seconds. A second test was performed where the real and reactive power across the switch $\mathrm{S} 1$ was zero. This case matched the local load with the output of the $100 \mathrm{~kW}$ generator. During this condition it was observed that both the ASCO SLTS and the Trace inverter continued to run on in an island condition for up to 40 seconds. It should be noted that this is not a normal operational mode for the ASCO SLTS and that the inverter did not trip because the 100 $\mathrm{kW}$ generator output was much larger than the inverter output and thus looked like a utility to the inverter. 


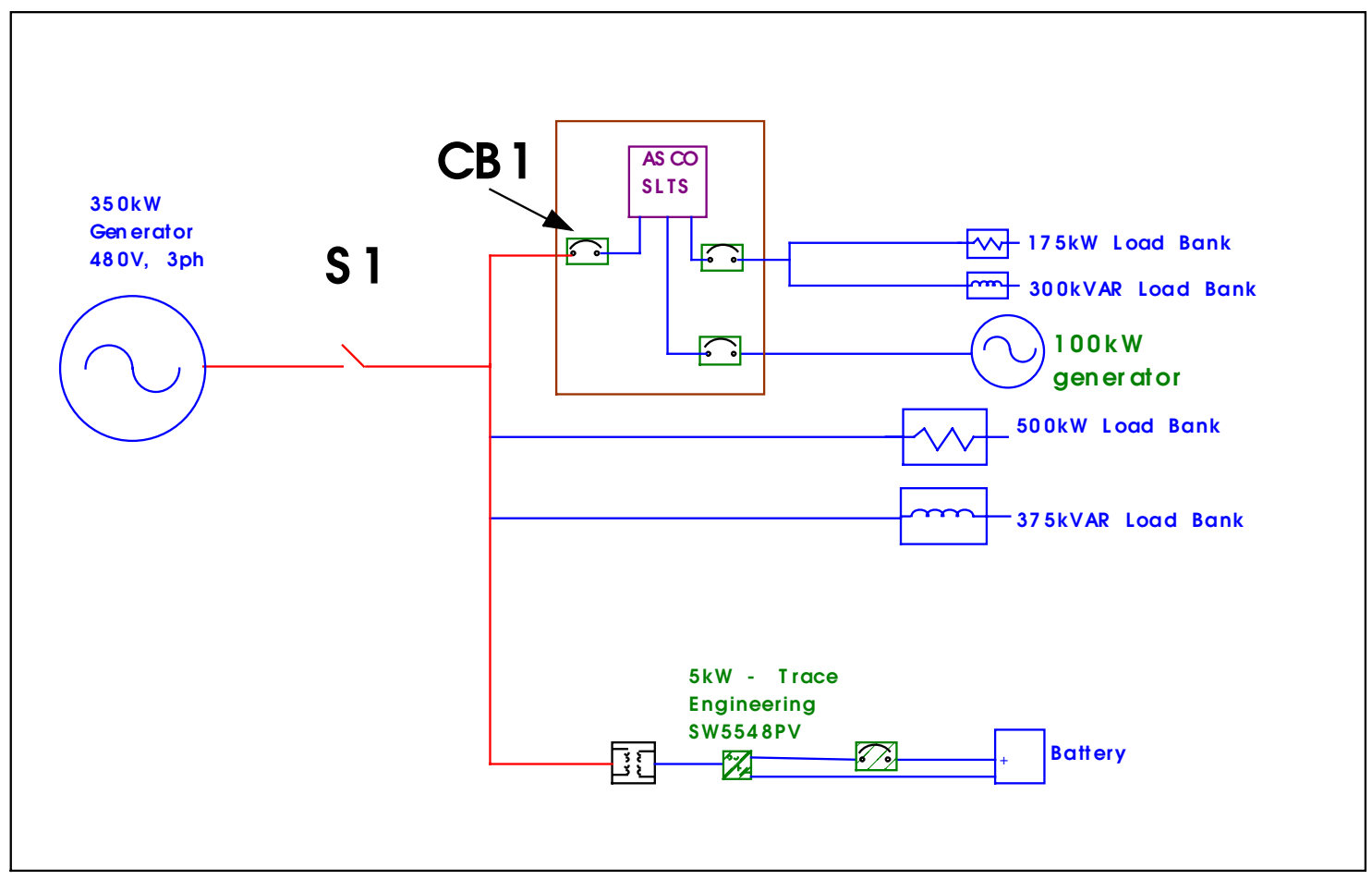

Figure 18. Electrical Diagram of Unintentional Island Test

\subsection{Lessons Learned conducting the Pilot Test}

\subsection{Comments on IEEE P1547 Procedures}

Several general lessons were learned with regard to conducting field verification of the interconnection tests required in IEEE P1547.

Need for Field Test Streamlining: Setting up the equipment and tests is labor and time intensive. Testing takes quite a few people to run equipment and collect data. Usually construction of the generation in the field does not include setting up equipment for taking detailed measurements, so typical electricians and mechanical installers are not used to dealing with accessibility requirements for data acquisition components.

Issues Presented by Use of Generator as Utility Simulator: The generator that was used as the utility simulator's nominal voltage was set to 460 instead of 480 . This was because of the built in protective features of the generator that only allowed an operational range of $420 \mathrm{~V}$ to $510 \mathrm{~V}$. Typically, generators are used to supply a constant voltage and frequency on all three phases. The utility simulator defined in IEEE P1547 needs to be a highly adjustable and have extremely good control over voltage and frequency on each phase. The generator that was used for the pilot testing had more than the usual amount of control for voltage and frequency, but still lacked the full range in voltage that was necessary for conducting the tests per IEEE P1547. The generator also did not have provisions for controlling individual phases. 


\subsection{ASCO 7000 SLTS}

The installation of the control wiring to the specific $100 \mathrm{~kW}$ generator utilized was problematic, but eventually fixed. This was the first time the 7000 had been connected to a Detroit Diesel generator.

On the matched load test for unintentional-islanding, the $100 \mathrm{~kW}$ generator could run on for up to 40 seconds. While this would not be a normal operational mode for the ASCO equipment, the test did prove that it is possible to sustain an island with a matched load.

\subsection{Trace Inverter}

The major issue with the testing of the Trace inverter was that the reset time after tripping was fixed at five minutes. This meant that the quickest that a set of five consecutive tests could be run was 30 to 60 minutes depending on data acquisition set up.

The unit did trip within required times for under voltage, under frequency, and over frequency, but the over voltage test could not be conducted to the required level because of the utility simulator protection limit discussed above..

On matched load (at the ASCO switch) for the anti-islanding test, the inverter did not sense that it was islanded for up to 40 seconds. The size of the $100 \mathrm{~kW}$ generator caused the inverter to act as if it were still connected to the utility.

\subsection{Data Acquisition}

Yokogawa 16-channel digital scope and Yokogawa PZ4000 provided the accuracy and speed to take these types of measurements. Their major drawback is in converting the data taken to user-friendly formats. The 16-channel scope was used to take data on the ASCO SLTS. The Yokogawa PZ4000 only has eight channels for inputs (4 voltage, 4 current). The PZ4000 was used to take data on the Trace inverter that is single phase, but to do three-phase measurements it is good to have at least 16 channels.

Two Power Measurement (PML) 7600s were used to back up the Yokogawa scope on the ASCO SLTS. These units had several built in features for measuring three-phase connections for energy usage and power quality. The most important finding in using the PML 76000s was that using the serial port connections are too slow for good data acquisition.

A Dranetz Power Platform 4300 was also used on the single-phase inverter system. It provided good capture of events but lacked multi-cycle data around events.

\subsection{Acknowledgments}

The authors would like to acknowledge all of the support from all who participated in the Distributed Power Program Pilot Test at the Nevada Test Site. These include: Earl Hodge (DOE/NV), Gary Seifert and Shawn West (INEEL), Tom Van Sittert and Larry Cohn (Bechtel/NV), and Jim Daley, Rob Siciliano, and Dan Hinton (ASCO Power Technologies). 


\section{Appendix A - Test Procedures from IEEE P1547 Draft 7}

These tests are included in this document to state the current test procedures that were recommended by the working group of IEEE P1547 when the testing at NTS was conducted.

\section{Over-voltage (Simulated Utility or Secondary Injection)}

1. Connect the DR unit under test to a simulated utility or secondary injection test set that is capable of varying the voltage and frequency.

2. With the simulated utility, or test set, and DR unit under test operating in parallel and output stabilized at $60 \mathrm{~Hz}$ plus or minus $0.25 \mathrm{~Hz}$ and 1.0 per unit voltage, ramp the phase A simulated voltage to $101 \%$ of the over-voltage setting at a rate not greater than $5 \%$ of the nominal voltage per second. Throughout the test, the frequency shall remain within $+/-0.4 \mathrm{~Hz}$ of $60 \mathrm{~Hz}$, and the voltage shall not exceed $105 \%$ of the setting value.

3. Verify that the interconnection system initiates disconnect of the DR within $+0 \%$ and $-5 \%$ tolerance of the prescribed time delay.

4. For three-phase DR, repeat the test for phases B and C.

5. Repeat each test five times. Failure to trip (cease to export power) for any one test shall constitute failure of the test.

6. Repeat the test for each of the over-voltage protection functions provided and adjust the ramp rate as necessary.

\section{Under-voltage (Simulated Utility or Secondary Injection)}

1. Connect the DR unit under test to a simulated utility or secondary injection test set that is capable of varying the voltage and frequency.

2. With the simulated utility, or test set, and DR unit under test operating in parallel and output stabilized at $60 \mathrm{~Hz}$ plus or minus $0.25 \mathrm{~Hz}$ and 1.0 per unit voltage; ramp the phase A simulated voltage to $99 \%$ of the under-voltage setting at a rate not greater than $5 \%$ of the nominal voltage per second. Throughout the test, the frequency shall remain within $+/-0.4 \mathrm{~Hz}$ of $60 \mathrm{~Hz}$, and the voltage shall not drop below $95 \%$ of the setting value.

3. Verify that the interconnection system initiates disconnect of the DR within $+0 \%$ and $-5 \%$ tolerance of the prescribed time delay.

4. For three-phase DR, repeat the test for phases B and C.

5. Repeat each test five times. Failure to trip (cease to export power) for any one test shall constitute failure of the test.

6. Repeat the test for each of the under voltage protection functions provided and adjust the ramp rate as necessary.

\section{Over-frequency (Simulated Utility or Secondary Injection)}

1. Connect the DR unit under test to a simulated utility or secondary injection test set that is capable of varying the voltage and frequency.

2. With the simulated utility, or test set, and DR unit under test operating in parallel and output stabilized at $60 \mathrm{~Hz}$ plus or minus $0.25 \mathrm{~Hz}$ and 1.0 per unit voltage; ramp the simulated frequency to $0.1 \mathrm{~Hz}$ above the over-frequency setting at a rate not greater 
than $0.5 \mathrm{~Hz}$ per second. Throughout the test, the voltage shall remain within $+/-5 \%$ of the nominal voltage, and the frequency shall not increase more than $0.2 \mathrm{~Hz}$ over the setting value.

3. Verify that the interconnection system initiates disconnection of the DR within $+0 \%$ and $-5 \%$ tolerance of the prescribed time delay.

4. Repeat each test five times. Failure to trip (cease to export power) for any one test shall constitute failure of the test.

\section{Under-frequency (Simulated Utility or Secondary Injection)}

1. Connect the DR unit under test to a simulated utility or secondary injection test set that is capable of varying the voltage and frequency.

2. With the simulated utility, or test set, and DR unit under test operating in parallel and output stabilized at $60 \mathrm{~Hz}$ plus or minus $0.25 \mathrm{~Hz}$ and 1.0 per unit voltage; ramp the simulated frequency to $0.1 \mathrm{~Hz}$ below the under frequency setting at a rate not greater than $0.5 \mathrm{~Hz}$ per second. Throughout the test, the voltage shall remain within $+/-5 \%$ of the nominal voltage, and the frequency shall not decrease more than $0.2 \mathrm{~Hz}$ below the setting value.

3. Verify that the interconnection system initiates disconnect of the DR within $+0 \%$ and $-5 \%$ tolerance of the prescribed time delay.

4. Repeat each test five times. Failure to trip (cease to export power) for any one test shall constitute failure of the test.

\section{Unintentional Islanding Test}

This test provides a means to determine that a DR or its interconnection system will not maintain stable operation without the presence of a utility source. A utility source means any source capable of maintaining an island within the recommended voltage and frequency window. An engine-generator with voltage and frequency control and with no non-islanding protection is considered a utility source for the purpose of this test. However, because of the uncertainty associated with the need to sink both real and reactive power from the $\mathrm{DR}$, this test can be performed most conveniently with a utility connection, rather than a simulated utility. The test should be conducted with voltage and frequency near the middle of their normal ranges. Voltage should be at least $3 \%$ inside the most restrictive voltage trip limits. Frequency should be at least $0.25 \mathrm{~Hz}$ inside the most restrictive frequency trip limits. (Note that frequency and voltage variation are not required for this testing.) 


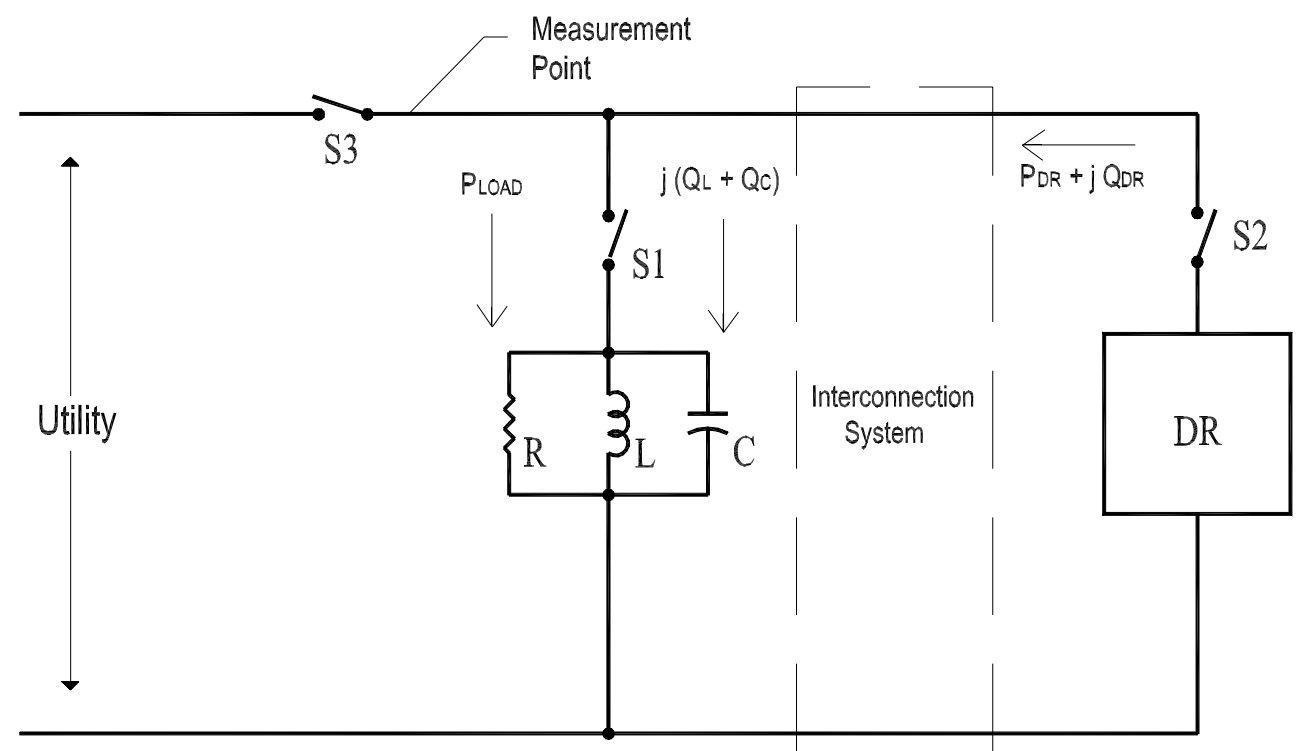

Figure A1. Non-islanding Test Circuit

This test procedure is designed to be universally applicable to both unity-power-factor DRs and non-unity-power-factor DRs. With unity-power-factor DRs, the second step, where $Q_{D R}$ is measured, will result in a value of $Q_{D R}$ that is zero, simplifying the remainder of the procedure. For DR's where $\mathrm{Q}_{\mathrm{DR}}$ is not zero the test procedure is complicated by the presence of reactive power to or from the DR.

Harmonic currents flow between the utility, the capacitor and the DR, complicating the situation by making it appear that current is flowing when the $60 \mathrm{~Hz}$ component of current has been reduced to zero. Thus it is important, when adjusting inductive and capacitive reactance, to use instruments that can read only the $60 \mathrm{~Hz}$ component of current and power.

The sequence of the steps below is suggested for several reasons. The inductance is adjusted first because that measurement is low in harmonics. The capacitance is added second so that the voltage is stable when the resistance is added. The resistive parallel load is then added and adjusted. Note that this resistance will be in addition to the resistance that will inherently be part of the inductive load.

This test procedure assumes that a non-unity-power-factor DR will be a source, not a sink for reactive power (i.e., $Q_{D R}$ is positive). However, the procedure will also work for DR's that sink reactive power ( $Q_{D R}$ is negative). The test circuit is configured as shown in Figure A1. Details of this circuit may be changed to suit the specific hardware available to the tester. For example, it may be convenient to replace switch S1 with individual switches on each leg of the RLC load. For each DR/load power combination the following procedure is suggested to achieve the proper generation-to-load complex power balance. 


\begin{tabular}{|c|c|}
\hline \multicolumn{2}{|c|}{ Table A1. Ratios of Real Load to DR Output } \\
\hline DR Output $\left(\mathbf{P}_{\mathrm{DR}}\right)$ & Real Power Load ( $\left.\mathbf{P}_{\text {LOAD }}\right)$ \\
\hline $25 \%$ & $25 \%$ \\
\hline $50 \%$ & $50 \%$ \\
\hline $100 \%$ & $100 \%$ \\
\hline $100 \%$ & $125 \%$ \\
\hline
\end{tabular}

a) Determine, from Table A1, the DR test output power, PDR, that will be used.

b) Begin with the utility switch S3 closed. With no local load connected (that is, S1 is open so that the RLC load is not connected at this time), start the DR and parallel it to the utility by closing S2. Operate the DR at the power output determined in step (a). Measure real and reactive power flow at the measurement point. The real power should equal PDR. The reactive power measured in this step is designated QDR.

c) Shut down the DR and open S2.

d) Adjust the RLC circuit to have a quality factor of 2.5. This is accomplished by:

1) Determining the amount of inductive reactance required in the resonant RLC circuit using the relation $\mathrm{QL}=2.5 \mathrm{PDR}$.

2) Connecting an inductor as the first element of the RLC circuit and adjusting the inductive reactance to yield the required value of $\mathrm{QL}$.

3) Connecting a capacitor in parallel with the inductor. Adjust the capacitive reactance so that $\mathrm{QC}+\mathrm{QL}=\mathrm{QDR}$.

4) Connecting a parallel resistance $R$ that results in the power consumed by the RLC circuit equaling PDR.

e) Connect the RLC load configured in step (d) to the circuit by closing S1. Start the DR and close S2, making certain that the DR power output is as determined in step (a). Note: The purpose of the procedure up to this point is to zero out the 60 Hertz components of real and reactive power, i.e., to zero out the $60 \mathrm{Hertz}$ component of current flow, at the utility switch S3. System resonances will typically generate harmonic currents in the test circuit. These harmonic currents may make it impossible to zero out an RMS measurement of power or current flow at the switch. Because of test equipment measurement error and some impact from harmonic currents, it is necessary to make small adjustments in the test circuit to achieve worst case islanding behavior. Step $(\mathrm{g})$ is performed to make these small adjustments.

f) Open the utility-disconnect switch to initiate the test. A test is successful when the DR ceases to energize the test load within the time limit set by 4.4.1.

g) After each successful test, one parameter ( $\mathrm{L}$ or $\mathrm{C}$ ) is adjusted by approximately $1.0 \%$ per test, within a total range of $\pm 5 \%$ of the operating point determined in step (d), above. The parameter that is adjusted may be load inductance, L, or load capacitance, C. After each adjustment, a non-islanding test is run and time to trip is recorded. If any of these tests results in islanding for longer than the time specified in 4.4.1, the unit fails the test and the test sequence is considered complete. 
h) The tests should be performed at each of the following ratios of real load (PLOAD)to DR output (PDR), where both values are given as a percent of DR rated output.

i) The actual tripping time for each test shall be recorded. A single failure of any of these tests is considered a failure of the entire test sequence. 


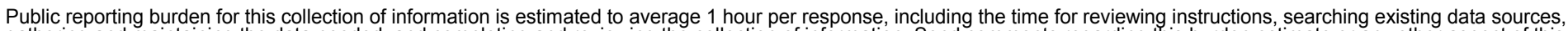

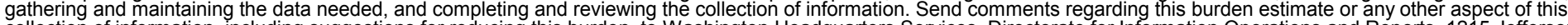
ing Headquarters Services, Directorate for Information Operations and Reports, 1215 Jefferson Davis Highway, Suite 1204, Arlington, VA 22202-4302, and to the Office of Management and Budget, Paperwork Reduction Project (0704-0188), Washington, DC 20503.
1. AGENCY USE ONLY (Leave blank)
2. REPORT DATE
May 2002
3. REPORT TYPE AND DATES COVERED
Technical Paper - Nov. 12-16, 2001

\section{TITLE AND SUBTITLE}

Distributed Power Program DER Pilot Test at the Nevada Test Site
5. FUNDING NUMBERS DPO2.1001

6. AUTHOR(S)

Benjamin Kroposki, Richard DeBlasio, Joseph Galdo

7. PERFORMING ORGANIZATION NAME(S) AND ADDRESS(ES)

National Renewable Energy Laboratory

1617 Cole Blvd.

Golden, CO 80401-3393

9. SPONSORING/MONITORING AGENCY NAME(S) AND ADDRESS(ES)

National Renewable Energy Laboratory

1617 Cole Blvd.

Golden, CO 80401-3393
8. PERFORMING ORGANIZATION REPORT NUMBER

NREL/TP-560-32063

10. SPONSORING/MONITORING AGENCY REPORT NUMBER

NREL/TP-560-32063

11. SUPPLEMENTARY NOTES

12a. DISTRIBUTION/AVAILABILITY STATEMENT National Technical Information Service

U.S. Department of Commerce

5285 Port Royal Road

Springfield, VA 22161

13. ABSTRACT (Maximum 200 words)

The DOE Distributed Power Program conducted a pilot test of interconnection test procedures November 12-16, 2001 at Area 25 of the Nevada Test Site (NTS). The objective of this pilot test was to respond to Congressional direction in the Energy and Water Development Appropriations Act of 2001 to complete a distributed power demonstration at the Nevada Test Site and validated interconnection tests in the field.

The demonstration consisted of field verification of tests in IEEE P1547 (Draft 7) that are required for interconnection of distributed generation equipment to electrical power systems. Some of the testing has been conducted in a laboratory setting, but the Nevada Test Site provided a location to verify the interconnection tests in the field. The testing also provided valuable information for evaluating the potential for the Nevada Test Site to host future field-testing activities in support of Distributed Energy Resources System Integration R\&D.

14. SUBJECT TERMS

Distributed Power Program; interconnection test; Nevada Test Site; NTS; Distributed Energy

17. SECURITY CLASSIFICATION OF REPORT Unclassified
18. SECURITY CLASSIFICATION OF THIS PAGE Unclassified
19. SECURITY CLASSIFICATION OF ABSTRACT Unclassified
15. NUMBER OF PAGES

16. PRICE CODE

20. LIMITATION OF ABSTRACT

UL 